\title{
Analysis of Landscape Dynamics, Trend Indicators and Evolutionary Trends in the Rusizi National Park (Burundi) from 1980 to 2015 by Remote Sensing and Field Investigations
}

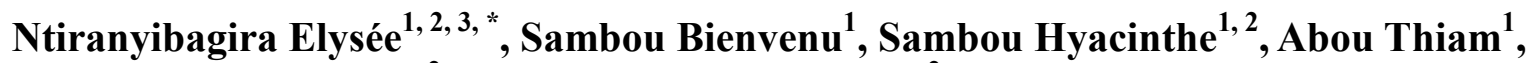 \\ Vieux Boukhaly Traore ${ }^{2}$, Mamadou Lamine Ndiaye ${ }^{2}$ \\ ${ }^{1}$ Institute of Environmental Sciences, Cheikh Anta Diop University of Dakar, Dakar, Senegal \\ ${ }^{2}$ Geoinformation Laboratory, Cheikh Anta Diop University of Dakar, Dakar, Senegal \\ ${ }^{3}$ Faculty of Agronomy and Bio-Engineering, Department of Environmental Sciences, National University of Burundi, Bujumbura, Burundi \\ Email address: \\ ebagira2010@yahoo.fr (N. Elysée), bienvenu.sambou@ucad.edu.sn (S. Bienvenu), sambouyas@gmail.com (S. Hyacinthe), \\ vieuxboukalytraore@yahoo.fr (V. B. Traore), louzemine@gmail.com (M. L. Ndiaye) \\ ${ }^{*}$ Corresponding author
}

\section{To cite this article:}

Ntiranyibagira Elysée, Sambou Bienvenu, Sambou Hyacinthe, Abou Thiam, Vieux Boukhaly Traore, Mamadou Lamine Ndiaye. Analysis of Landscape Dynamics, Trend Indicators and Evolutionary Trends in the Rusizi National Park (Burundi) from 1980 to 2015 by Remote Sensing and Field Investigations. American Journal of Environmental Protection. Vol. 6, No. 2, 2017, pp. 31-49. doi: 10.11648/j.ajep.20170602.12

Received: February 28, 2017; Accepted: March 10, 2017; Published: March 24, 2017

\begin{abstract}
Nowadays, adaptive management of protected areas is lacking objective and integrated indicators for rigorous assessment of their evolutionary trends and the effectiveness of the conservation methods on the basis of conservation objectives and landscape dynamics. The study provides a methodological approach for determining trend indices and historical evolutionary trends which describe the developments of the Rusizi Park known to be the most threatened protected area in Burundi. The study is based on the diachronic analysis of land cover using multi-date Landsat images from 1984, 1990, 2011, 2000 and 2015 and field data. The supervised classification of the images made it possible to identify 9 to 10 land cover classes with contrasting evolutions. The park's matrix, which was made of wooded savannah in 1984 with $43.78 \%$, consists of shrub savannah and cultivated areas occupying $25.87 \%$ and $25.40 \%$ by 2015 . The results showed that during the periods $1984-1990$, 1990-2000, 2000-2011 and 2011-2015, the park experienced alternating positive and negative evolutions whose trend indices are $\mathrm{T}_{\mathrm{i}}[(38,6) ; 2 \mathrm{D}] ; \mathrm{T}_{\mathrm{i}}[(65,22) ; 3 \mathrm{D}] ; \mathrm{T}_{\mathrm{i}}[(78,-82) ; 4 \mathrm{a}]$ and $\mathrm{T}_{\mathrm{i}}[(58,-36) ; 3 \mathrm{c}]$; the second and the third periods being the most devastating and beneficial ones for conservation. Finally, between 1984 and 2015, the park undergone a negative evolution of trend index $\mathrm{T}_{\mathrm{i}}[(77,-64), 4 \mathrm{~b}]$ characterized by "a very strong evolution (4)" with "a strong negative trend (b)" which is represented by spatial transformations affecting $77 \%$ of the park, consisting of $82 \%$ degradation and $18 \%$ increase, resulting in a negative result of $64 \%$. During that time, the park lost $29.9 \%$ of the vegetation cover and $31.2 \%$ of water resources in favor of anthropized areas, which increased by $94.5 \%$. The decline of the vegetation cover is dominated by savannah and forest loss dynamics. Land cover changes are mainly caused by anthropogenic pressures and the variability of climatic conditions. They are due to six spatial processes which are dominated by patch creation and patch attrition. The results also revealed a high degree of coherence between spatial processes, class dominance and trend indicators. In general, class dominance decreases are linked to patch degradation processes and vice versa. Patch degradation processes such as fragmentation lead to negative evolutions if they affect vegetation and positive developments when they affect anthropized zones and vice versa, for patch development processes like enlargement.
\end{abstract}

Keywords: Rusizi National Park, Landsat Image, Land Cover, Spatial Structure Index, Class Dominance, Trend Index, Evolutionary Trend 


\section{Introduction}

The Rusizi National Park is known to be the only protected area in Burundi that has an international status as a Ramsar site. It is also the most threatened protected area and the most unstable $[1,2]$. Its conservation status has indeed changed three times since its creation in 1980. The human pressures that the protected area is facing bring continuous biodiversity degradation of which real processes and magnitude are still unknown $[3,4,5,6]$. Therefore, it is necessary to evaluate the evolution and the strategies for the conservation of the protected area using objective and rigorous indicators. Indeed, as shown, by some studies, monitoring and characterizing the evolution of protected area habitats and ecosystems are essential strategies for fruitful biodiversity management $[7,8$, 9].

The study is an integrated analysis of the park evolution processes, trends and factors which is based on the combinatory use of a constructed trend index and landscape ecology tools $[10,11,12]$. It analyses and compares the spatio-temporal changes that marked the protected area from 1984 to 2015, under its statutes of Reserve (1980-1990, 2000-2011) and Parc (1990-2000, 2011-2015) for the evaluation of the conservation statements and the quality of the management with reference to the conservation objectives and desired evolutions [13, 14].

The research aims to: (1) analyze the landscape transformations and changes, (2) determine the spatial indicators and processes carrying the observed dynamics (3) construct a trend index and determine the evolutionary trends of the protected area and (4) analyze the coherence between evolution indicators, processes and trends.

\section{Methodology}

The methodology we used for the study of landscape dynamics and trend indicators of the Rusizi National Park from 1984 to 2015 is based on the diachronic analysis of land cover. On one hand, it relies on satellite imagery and geographic information systems for the characterization of changes in land cover and the determination of evolutionary trends $[15,16,17,18,19]$. On the other hand, it makes use of field investigations for socio-economic and climatic data to explain the results from the cartographic analysis.

\subsection{Study Area}

The Rusizi national Park is one of the seventeen protected areas of Burundi which is located about ten kilometers from the city of Bujumbura, in its extension zone. It extends over the Gihanga commune in Bubanza province and Mutimbuzi commune in the province of Bujumbura.

It is bounded on the west by the D. R. Congo, on the south by Lake Tanganika, on the east by National Road 5 and on the north by the province of Cibitoke. It consists of the Palmeraie sector in the north, the Delta sector in the south, the Grande Rusizi corridor and two buffer zones covering a total area of 10,673 ha (Figure 1).

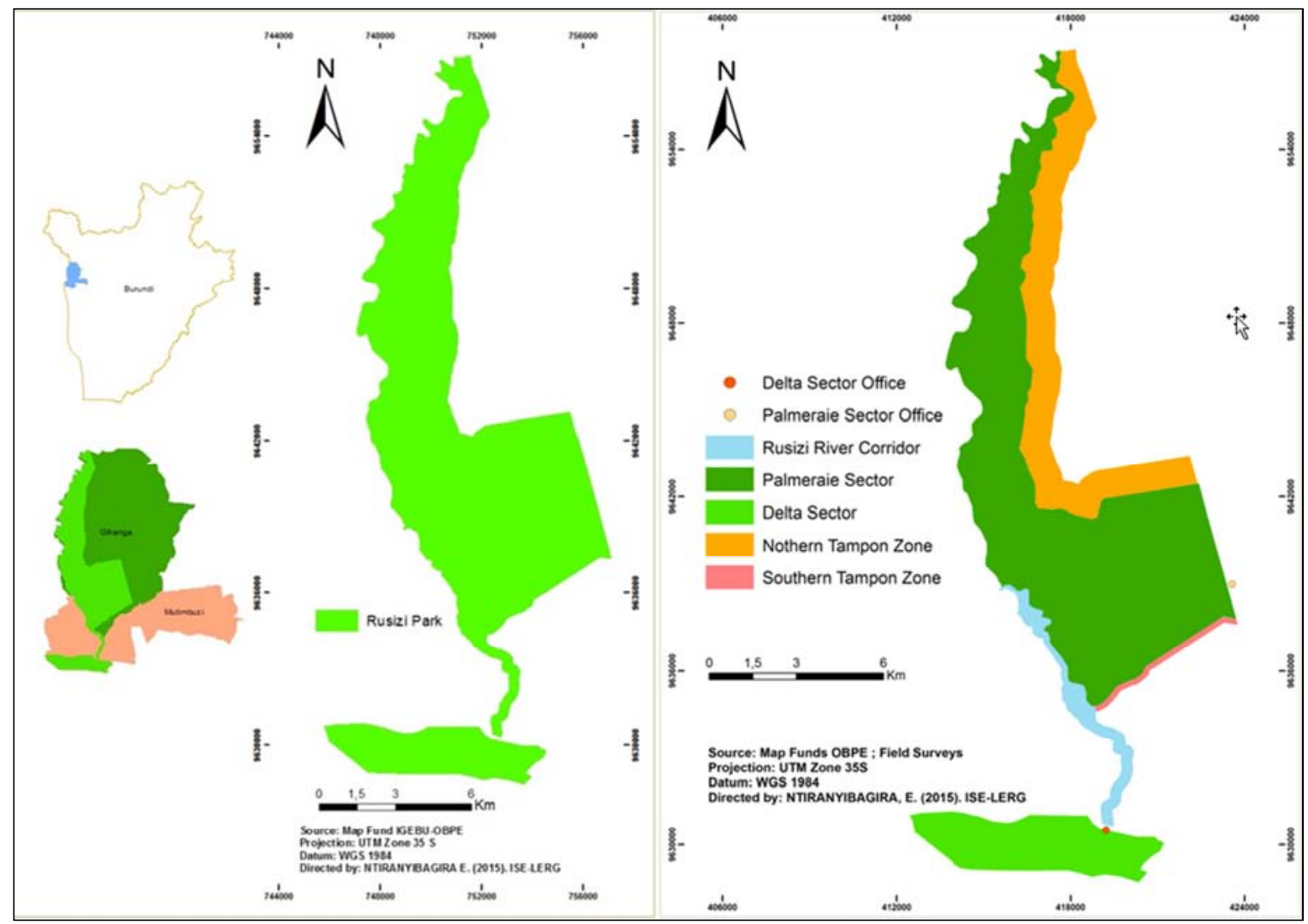

Figure 1. Location and physical layout of the Rusizi National Park. 
Climatically, the park belongs to the Rusizi plain, which is the lowest and most arid area in the country with an AW4s climate in the Köppen classification [5]. The region is characterized by an altitude of between $775 \mathrm{~m}$ and $1000 \mathrm{~m}$, cyclical rainfall of no more than $900 \mathrm{~mm} /$ year, average monthly temperatures of $23^{\circ} \mathrm{C}$ to $24.5^{\circ} \mathrm{C}$ and longer and longer dry seasons [20].

The Rusizi Park location in a peri-urban area with a high migration rate and a rapid growing population exposes it to intense land pressures fueled by important political and economic stakes, which are reflected in endless changes in conservation status.

\subsection{Image Data Sets}

\subsubsection{Choice of Images}

We used multi-date and ortho-rectified and georeferenced Landsat images from the study area which is covered by the Path/Row173-062 scene. These are Landsat Thematic Mapper (TM) images from 1984, 1990 and 2011, 2000 Enhanced Thematic Mapper (ETM) and 2015 Operational Land Imager and Thermal Infrared Sensor (OLI-TIRS), which correspond to significant landmarks in the conservation history of the protected area and express reference states for comparison of successive evolutions. The 1984 image is the first clear image of the study area since the creation of the Rusizi Reserve in 1980. The images of 1990, 2000 and 2011 mark successive passages from Reserve status to that of Park and the status of Park to that of Reserve. The 2015 image was chosen to assess the effects of the 2011 status change on the quality of conservation. The images used were acquired at the beginning of the dry season in order to have a maximum differentiation of the elements of land cover, in this case that of the herbaceous and woody ones [21].

\subsubsection{Image Processing}

The images were processed and analyzed using the Envi 4.5 software. After cutting the images on the study area, a 5-4-3 colored composition in the short infrared $(1.550-1.750 \mu \mathrm{m})$, near-infrared $(0.730-0.900 \mu \mathrm{m})$ and red $(0.630-0.690 \mu \mathrm{m})$ was applied to the 1984, 1990, 2000 and 2011 images for better discrimination of land cover units and easy detection of changes $[22,21]$.

For the 2015 image, the 6-5-4 colored composition was carried out in the short infrared $(1.560-1.660 \mu \mathrm{m})$, near-infrared $(0.845-0.885 \mu \mathrm{m})$ and red $(0.630-0.680 \mu \mathrm{m})$. The classification of the images was done in a supervised way, according to the maximum likelihood algorithm which calculates the probability of belonging of the pixels to a precise class of land cover based on the postulate that the signature spectrum of the pixels is representative of their class of belonging $[23,24]$.

The quality of the classification was assessed using confusion matrices and parameters such as overall accuracy and Kappa coefficient [25, 18]. The field validation of image classification was performed using ground control point samples for the most recent image (2015). First, it was based on the results of previous studies $[26,4,5]$. Second, it was done using semi-directive interviews with older staff for older images $(1984,1990,2000,2011)$. As a result of the classification of images, eleven different land cover classes were identified: ${ }^{1}$ Hyphaene benguellensis forest, ${ }^{2}$ dense forest relics, ${ }^{3}$ wooded savannah, ${ }^{4}$ shrub savannah, ${ }^{5}$ grassland savannah, ${ }^{6}$ aquatic vegetation, ${ }^{7}$ water bodies, ${ }^{8}$ bare soils, ${ }^{9}$ cultivated areas, ${ }^{10}$ built-up areas and ${ }^{11}$ burned areas. After validation, the image classifications were homogenized by the application of a Kernel $3 \times 3$ majority filter and automatically vectorized in Envi 4.5 software.

\subsubsection{Cartographic Analyzes}

The raw results of the filtered and vectorized classifications were exported to ArcGIS 10.1 for mapping, cartographic analyzes and extraction of land cover statistics. They were first projected in the World Geodesic System (WGS 1984), Universal Transverse Mercator (UTM) Zone $35 \mathrm{~S}$ before being then set to the physical limits of the park. Coupled crosses of land cover maps revealed land cover changes that are reflected in the transition matrices [27, 28].

The analysis of the transition matrices of the studied periods made it possible to identify and extract the "zones of stability" and the "areas of change" which are either "modifications" or "conversions" [29, 30, 31]. The appropriate meanings of these concepts regarding the case study are defined below. The interannual dynamics of land cover classes were analyzed using the spatial expansion rate $\left(\mathrm{T}_{\mathrm{a}}\right)$ which is calculated by the formula: $\mathrm{Ta}=100 * \frac{\mathrm{S} 2-\mathrm{S} 1}{\mathrm{~S} 1}$ (1), where $S_{1}$ and $S_{2}$ respectively represent the areas of a given class in year $t_{1}$ and year $t_{2}$ [32].

\section{Spatial Indices and Processes}

The spatial structure indices of natural ecosystems constitute an important factor of evolution according to several authors $[12,33,34,35]$. The parameters characterizing the spatial transformation processes used to describe the landscape configuration are the number (n), the area (a) and the perimeter (p) of the patches of the landscape units $[36,37]$.

In our study, patches are the elementary polygons of the land cover classes as they appear in the raw export results of images classified from the Envi 4.5 software to the ArcGIS 10.1 software. The comparison of the homologous values of a parameter between two dates $\mathrm{T}_{0}\left(\mathrm{n}_{\mathrm{t} 0}, \mathrm{a}_{\mathrm{t} 0}, \mathrm{p}_{\mathrm{t} 0}\right)$ and $\mathrm{T}_{1}\left(\mathrm{n}_{\mathrm{t} 1}, \mathrm{a}_{\mathrm{t} 1}\right.$, $\mathrm{p}_{\mathrm{t} 1}$ ) makes it possible to determine the spatial processes at work in a landscape transformation by means of the "Decision tree algorithm" used in landscape ecology [10, 37, 38].

This model defines ten spatial processes corresponding to ten geometries, which are namely: (a) aggregation, (b) attrition, (c) creation, (d) deformation, (e) dissection, (f) fragmentation, (g) enlargement, (h) perforation, (i) shift and (j) shrinkage (Figure 2). 


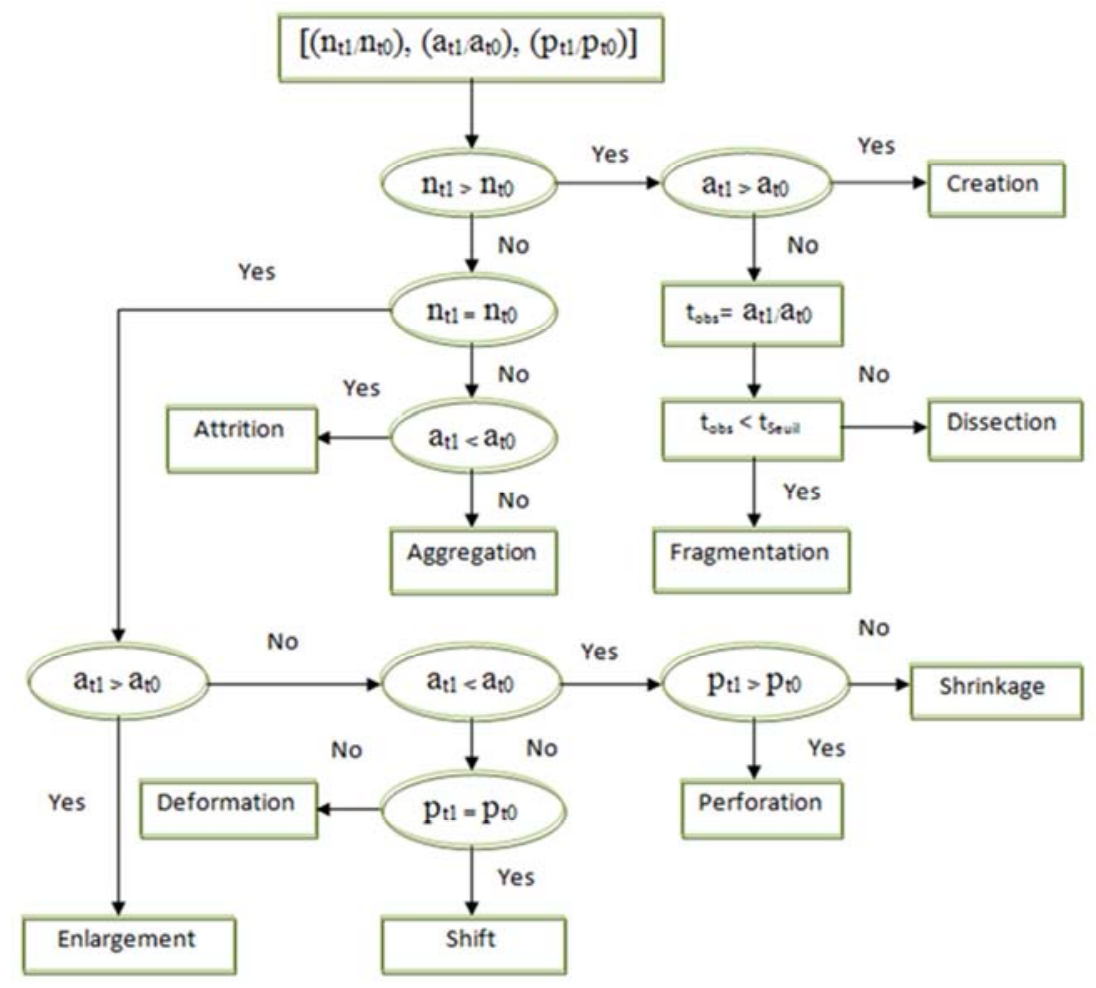

Figure 2. Decision tree algorithm [38] derived from [37].

The input data for the calculation of the spatial structure indices and the definition of the spatial transformation processes between 1984 and 2015 are the number (n), the area (a) and the perimeter ( $p$ ) of patches for the different land cover classes of each year. For a given land cover class, the values of (n) were determined by the number of elementary polygons in the attribute table of the imported results from image classification prior to their merger. The values of (p) and (a) were determined after the elementary polygons were merged into thematic classes. For the considered periods, the related values that were compared each other are respectively $\left(\mathrm{n}_{1990} / \mathrm{n}_{1984}, \quad \mathrm{a}_{1990} / \mathrm{a}_{1984}, \quad \mathrm{p}_{1990} / \mathrm{p}_{1984}\right), \quad\left(\mathrm{n}_{2000} / \mathrm{n}_{1990}, \mathrm{a}_{2000} / \mathrm{a}_{1990}\right.$, $\left.\mathrm{p}_{2000} / \mathrm{p}_{1990}\right), \quad\left(\mathrm{n}_{2011} / \mathrm{n}_{2000}, \quad \mathrm{a}_{2011} / \mathrm{a}_{2000}, \mathrm{p}_{2011} / \mathrm{p}_{2000}\right), \quad\left(\mathrm{n}_{2015} / \mathrm{n}_{2011}\right.$, $\left.\mathrm{a}_{2015} / \mathrm{a}_{2011}, \mathrm{p}_{2015} / \mathrm{p}_{2011}\right)$ and $\left(\mathrm{n}_{2015} / \mathrm{n}_{1984}, \mathrm{a}_{2015} / \mathrm{a}_{1984}, \mathrm{p}_{2015} / \mathrm{p}_{1984}\right)$. In cases where $\left(n_{t 1}>n_{t 0}\right)$ and $\left(a_{t 1}<a_{t 0}\right)$, two spatial processes are possible; namely fragmentation and dissection. In the study, we took an arbitrary value of 0.5 . Thus, if $t_{\text {obs }} \leq 0.5$, we considered that the spatial process involved is fragmentation. If not $\left(\mathrm{t}_{\mathrm{obs}}>0.5\right)$, this is dissection. This is due to the fact that there is no yet scientific consensus on the threshold value $\left(t_{\text {obs }}\right.$ $\left.=\mathrm{a}_{\mathrm{t} 1} / \mathrm{a}_{\mathrm{t} 0}\right) \varepsilon[0,1]$ to be considered to differentiate them $[37,38]$.

The input data for the calculation of the spatial structure indices and the definition of the spatial transformation processes between 1984 and 2015 are the number (n), the area (a) and the perimeter (p) of patches for the different land cover classes of each year. For a given land cover class, the values of (n) were determined by the number of elementary polygons in the attribute table of the imported results from image classification prior to their merger. The values of (p) and (a) were determined after the elementary polygons were merged into thematic classes. For the considered periods, the related values that were compared each other are respectively $\left(\mathrm{n}_{1990} / \mathrm{n}_{1984}, \quad \mathrm{a}_{1990} / \mathrm{a}_{1984}, \quad \mathrm{p}_{1990} / \mathrm{p}_{1984}\right), \quad\left(\mathrm{n}_{2000} / \mathrm{n}_{1990}, \mathrm{a}_{2000} / \mathrm{a}_{1990}\right.$, $\left.\mathrm{p}_{2000} / \mathrm{p}_{1990}\right), \quad\left(\mathrm{n}_{2011} / \mathrm{n}_{2000}, \mathrm{a}_{2011} / \mathrm{a}_{2000}, \mathrm{p}_{2011} / \mathrm{p}_{2000}\right), \quad\left(\mathrm{n}_{2015} / \mathrm{n}_{2011}\right.$, $\left.\mathrm{a}_{2015} / \mathrm{a}_{2011}, \mathrm{p}_{2015} / \mathrm{p}_{2011}\right)$ and $\left(\mathrm{n}_{2015} / \mathrm{n}_{1984}, \mathrm{a}_{2015} / \mathrm{a}_{1984}, \mathrm{p}_{2015} / \mathrm{p}_{1984}\right)$. In cases where $\left(\mathrm{n}_{\mathrm{t} 1}>\mathrm{n}_{\mathrm{t} 0}\right)$ and $\left(\mathrm{a}_{\mathrm{t} 1}<\mathrm{a}_{\mathrm{t} 0}\right)$, two spatial processes are possible; namely fragmentation and dissection. In the study, we took an arbitrary value of 0.5 . Thus, if $t_{\text {obs }} \leq 0.5$, we considered that the spatial process involved is fragmentation. If not $\left(\mathrm{t}_{\mathrm{obs}}>0.5\right)$, this is dissection. This is due to the fact that there is no yet scientific consensus on the threshold value $\left(t_{\text {obs }}\right.$ $\left.=\mathrm{a}_{\mathrm{t} 1} / \mathrm{a}_{\mathrm{t} 0}\right) \varepsilon[0,1]$ to be considered to differentiate them $[37,38]$.

\section{Dominance of Land Cover Classes}

The dominance of a land cover class is defined by the formula: $D(a)=\frac{\mathrm{Amax}}{\mathrm{At}} * 100$ (2) where $\mathrm{A}_{\max }$ is the area of the largest patch of the class and At its total area [11, 38]. The dominance was used to quantify the levels of class fragmentation or consolidation associated with the evolution processes. The higher the dominance of a class is, the less its fragmentation is and vice versa.

For the different years and land cover classes, the dominance values were determined in two steps. First, we have identified the most extensive polygon in the attribute table of the imported result from image classification and noted its area. The total area of the class was calculated after the merge of all the polygons of the attribute table. For the dominance calculation, $A_{\max }$ and $A_{t}$ were then entered in the formula (2).

\section{Trend Indices and Evolutionary Trends}

The protected area trend index $\left(\mathrm{T}_{\mathrm{I}}\right)$ is a synthetic indicator designed to quantify and qualify the overall evolutionary trend of 
a protected area over a period of time. The purpose of the index is to provide an objective and periodic assessment of the effectiveness of conservation measures in order to ensure adaptive management. The basic principle of the method of determining the index is the adjustment of the quantitative and qualitative changes in the specific classes of land cover to the conservation objectives of a protected area. Since the Rusizi Park's long-term conservation objective is the "protection of original and natural vegetation and the fight against soil erosion", the development of vegetation cover and the decline of non-vegetation areas is the main goal of its conservation $[3,1]$. Consequently, "regressions (R)" and "neutral conversions $\left(\mathrm{C}_{\mathrm{n}}\right)$ ", which we respectively define as "quantitative and qualitative losses of vegetation" and "reciprocal conversions between non vegetation classes", are negative or neutral processes contrary to the evolutions expected. Conversely, "progressions (P)" and "stabilities (S)", which we define as "quantitative and qualitative gains of vegetation" and "maintaining ecosystems as they are", are beneficial processes for conservation. This means that any land cover conversion involving a vegetation class is either a regression or a progression. Qualitative gains of vegetation (positive modifications) and qualitative losses of vegetation (negative modifications) refer to the natural and spontaneous evolution of vegetation [39]. Meanwhile, quantitative gains of vegetation (positive conversions) and quantitative losses of vegetation (negative conversions) are directed towards physical appearances and disappearances of vegetation, whatever their nature. The trend index calculation ultimately focuses on comparing the regressions, progressions, neutral conversions and overall stability values that constitute the input data in the computational model (Figure 3). The index incorporates three variables: "change rate " $\left(\mathrm{T}_{\mathrm{c}}\right)$, "change dominating direction" and "change balance value $\left(\mathrm{B}_{\mathrm{c}}\right)$ ". The rate of change represents the proportion of spatial changes $T c=100-\mathrm{S}$ (3) where $\mathrm{S}$ is the overall stability $(\%)$. The direction of change is the negative or positive sign of the difference between relative progression (X) and relative degradation $(\mathrm{Y})$. The relative progression and degradation values $(\mathrm{X})$ and $(\mathrm{Y})$ result from a mathematical linearization which recalculates the absolute progression $(\mathrm{P})$ and the absolute degradation (D) with respect to the rate of change considered to be representing $100 \%$ of the protected area. The balance value is the absolute value of the difference between the two quantities. When the difference between $\mathrm{X}$ and $\mathrm{Y}$ is positive, the overall evolutionary trend of the protected area is positive. When it is negative, the evolutionary trend is negative. When the change balance is equal to zero, the evolutionary trend is determined by the relative importance of the rate of change $T_{c}$ and the global stability $\mathrm{S}$. Here, the threshold value considered for the stability $\left(\mathrm{S}_{\text {seuil }}\right)$ is equal to $50 \%$. This is the solution of the equation $(S=T c) \Leftrightarrow(S=100-S)$ (4). Assuming that in the conservation field "stability is less than progression and better than degradation", we consider that for equal relative progression and degradation corresponding to the equation $X-\mathrm{Y}=0 \Leftrightarrow$ $\mathrm{Bc}=0$ (5), the better the stability is, the better the evolution is and vice versa. If the measured stability $\mathrm{S}_{\mathrm{obs}} \geq \mathrm{S}_{\text {seuil, }}$, the evolutionary trend will be said to be positive. Otherwise, it will be said to be negative (Figure 3).

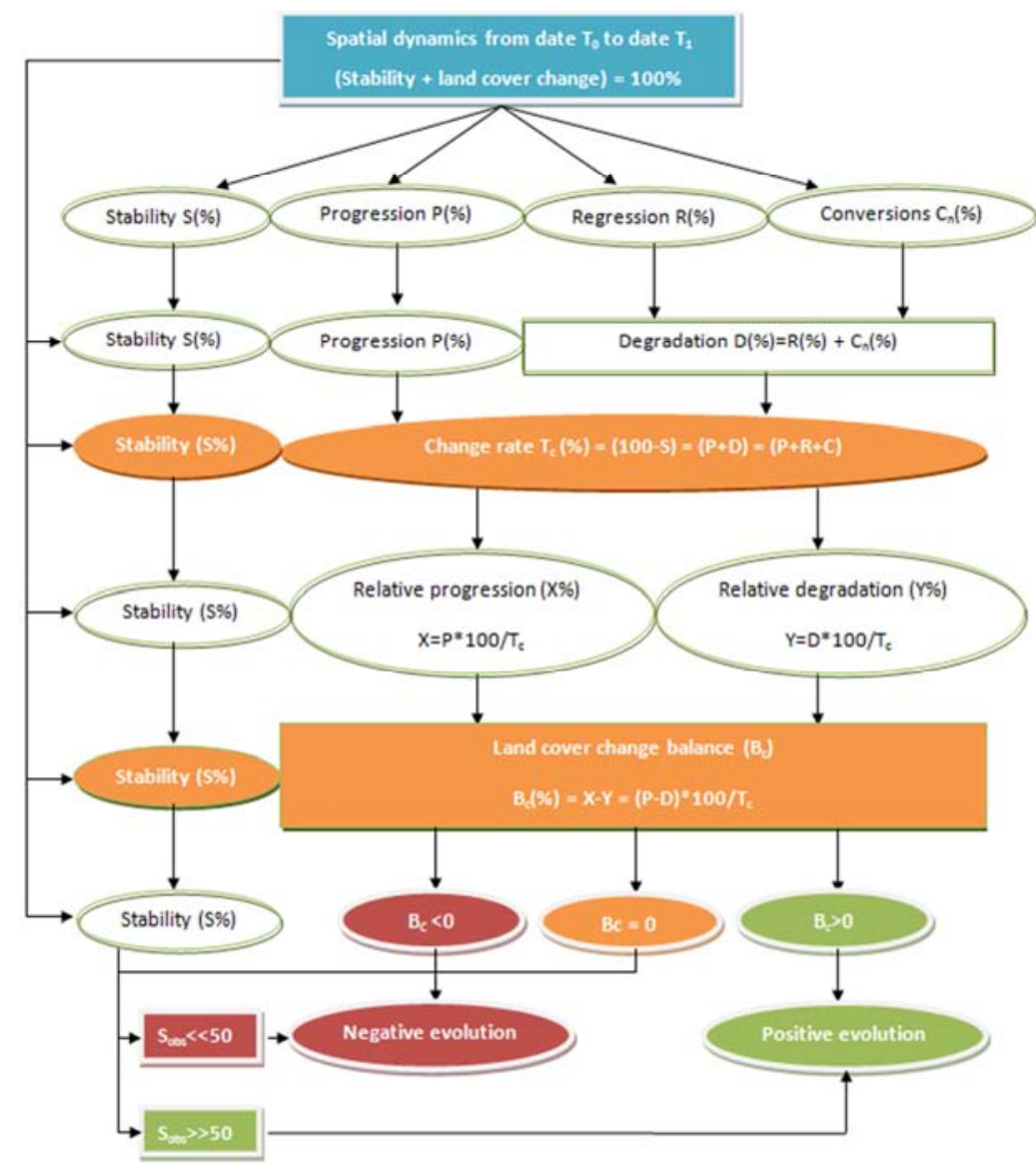

Figure 3. Theoretical and operational model proposed for determination of trend index. 
Parameters $\mathrm{S}, \mathrm{P}, \mathrm{R}$ and $\mathrm{C}_{\mathrm{n}}$, which make it possible to calculate $\mathrm{D}, \mathrm{X}, \mathrm{Y}, \mathrm{T}_{\mathrm{c}}$ and $\mathrm{B}_{\mathrm{c}}$, are directly derived from land cover transition matrices. The values of $T_{c}$ and $B_{c}$ resulting from the calculations are placed in the appropriate cells of the grid proposed for the trend index classification (Table 1). In the grid, the change rates are divided into four classes of $25 \%$ intervals, which translate, by increasing values "a low evolution" coded (1), "a moderate evolution" coded (2), "a strong evolution" coded (3) and " a very strong evolution" coded (4). Change balances are divided into eight classes of $25 \%$ intervals with four classes of negative values at the top and four classes of positive values at the bottom. Negative balance classes mean, by increasing values, "a very strong negative trend" coded (a), "a strong negative trend" coded (b), "a moderate negative trend" coded (c) and "a low negative trend" coded (d). Positive balance classes express by increasing values "a low positive trend" coded (D), "a moderate positive trend" coded (C), "a strong positive trend" coded (B) and "a very strong positive trend" coded (A). The classes of negative balances (a to d) and positive balances ( $D$ to $A$ ) are symmetrical with respect to the value axis $B c=0$ (6) Trend indices are therefore alphanumeric combinations ranging from (1d) to (4a) and (1D) to (4A) for extreme negative and positive trends. The interpretation of their values is done through a combinatorial reading of the labels of the change rates and the change balances (Table 1).

Table 1. Trend indices assessment and classification grid.

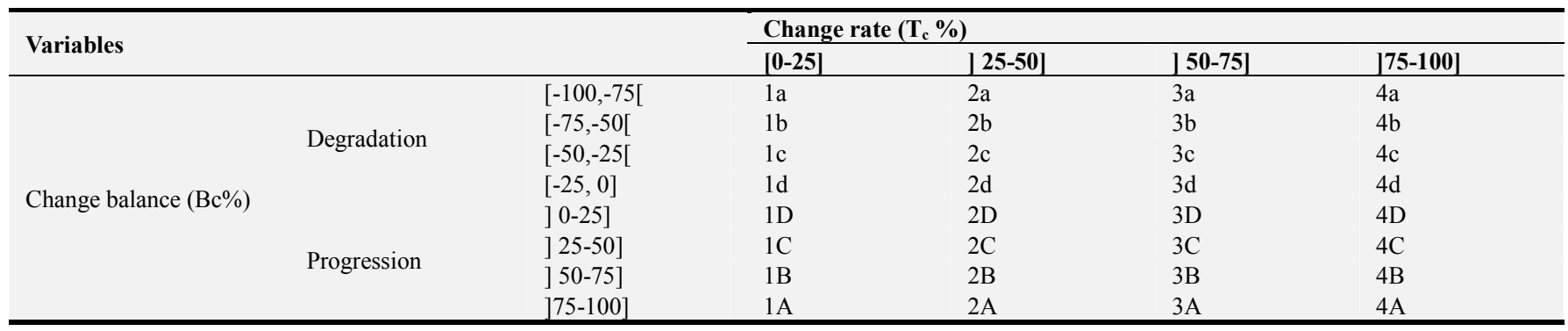

The results of calculations of the trend indices for the study periods were presented to the successive park chiefs and the eldest rangers for validation. The validation process was achieved through semi-structured interviews based on the trend index assessment and classification grid above.

\section{Results}

\subsection{Image Classification Accuracy and Quality}

The results of the classifications of the images give precision levels between $85.54 \%$ and $91.02 \%$ for the general precision and between $83.53 \%$ and $89.68 \%$ for the Kappa coefficient. Such precision levels are sufficiently high compared to the recommended thresholds for overall accuracy
[40] and the Kappa coefficient [41]. These levels of accuracy are the more excellent as the number of classes identified on each image is high [42]. The analysis of the confusion matrices showed that land cover classes are generally well discriminated. However, levels of confusion of classes up to $18 \%$ have been observed for some classifications. The confusion between anthropized classes (cultivated areas, built-up areas and bare soils) and vegetation classes (wooded savannah and shrub savannah) could be explained by the presence and dispersal of significant illegal activities within the park. The confusion between vegetation classes (grassland savannah, Hyphaene benguellensis forest, aquatic vegetation) would be linked to the diffuse nature of their spatial boundaries given their strong imbrications in each other.

\subsection{Evolution in Land Cover}

\subsubsection{Land Cover From 1984 to 2015}

불 $1984=2090=2000=2011=2015$

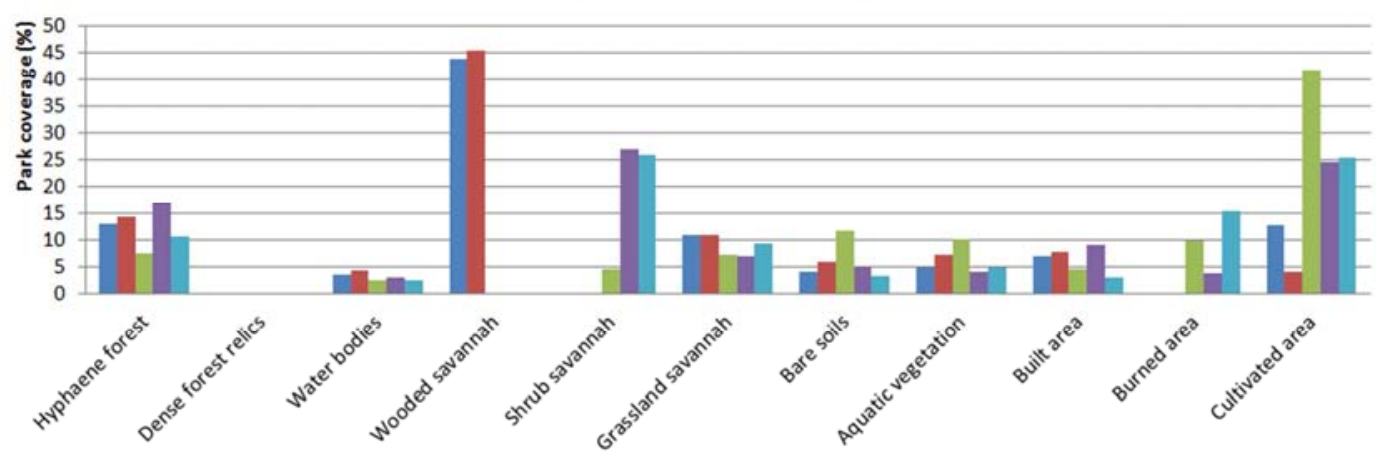

Figure 4. Typology and evolution of land cover classes from 1984 to 2015. 
As shown in figure 4, the number and size of land cover classes has evolved in contrasting ways. In 1984 and 1990, it was the wooded savannah that formed the dominant matrix of the park, with $43.78 \%$ and $45.23 \%$ of the park; i.e. 4674 ha and 4827 ha, respectively. In 2000, the cultivated areas formed the dominant matrix, with $41.54 \%$ of the total area; i.e. 4441 ha. We are witnessing the disappearance of the wooded savannah raised by deforestation and the progressive appearance of a shrub savannah of substitution. In 2011, the shrub savannah and cultivated areas co-dominate the landscape matrix with $26.88 \%$ and $24.63 \%$ of the park's surface; i.e. 2869 ha and 2629 ha. This year saw the disappearance of dense forest relics and a remarkable extension of the shrub savannah and Hyphaene benguellensis forest. In 2015, the landscape matrix is co-dominated by the shrub savannah and cultivated areas which occupy $25.87 \%$ and $25.40 \%$; i. e. 2761 ha and 2711 ha, respectively. The year 2015 saw a considerable extension of the burned areas, which together with the cultivated areas constitute the most important anthropized classes of the park.

The results showed a shift from ten land cover classes in 1984, 1990 and 2000 to nine land cover classes in 2011 and 2015. The vegetation cover which represented $72.49 \%$ (7739 ha) in 1984 , first rose to $77.87 \%$ (8312 ha) in 1990 , then to $29.71 \%$ (3172 ha) in 2000, then to $54.63 \%$ (5832 ha) in 2011 and finally to $50.83 \%$ ( $5425 \mathrm{ha}$ ) in 2015 . Cultivation clearings, intense tree cuts for domestic needs, bush fires and overgrazing explain the significant destruction of the vegetation cover especially between 1990 and 2000.

\subsubsection{Land Cover Changes Between 1984 and 2015}

The periodic changes in land cover were illustrated by the transition matrices whose analysis showed significant variations depending on the magnitude of the natural and anthropogenic factors involved. Between 1984 and 1990, the most important land cover area transfers were modification of grassland savannah in Hyphaene benguellensis forest (2.08\%), conversion of wooded savannah into bare soil $(2.25 \%)$ and built-up areas (4.98\%), conversion of cultivated areas into grassland savannah (1.76\%), Hyphaene benguellensis forest $(2.19 \%)$ and wooded savannah $(5.87 \%)$ and conversion of built-up areas into wooded savannah (3.25\%) (Table 2). The most stable land cover classes are wooded savannah (33.62\%), Hyphaene benguellensis forest (9.03\%), grassland savannah $(6.34 \%)$ and aquatic vegetation (3.45\%) which represent $85 \%$ of the overall stability, covering $62 \%$ of the park (Table 2 , Figure 6); i.e. 6592 ha. Changes resulted in a $7.4 \%$ extension of the vegetation cover from 7739 ha to 8312 ha and a $25.7 \%$ reduction in anthropized zones from 2,573 ha to 1912 ha. Cultivated areas and aquatic vegetation experienced the most important changes. They moved from 1357 ha to 436 ha and from 516 ha to 779 ha. This corresponds to a $67.9 \%$ decline and a $51.2 \%$ increase.

Table 2. Transition matrix in land cover between 1984 and 1990 (\%).

\begin{tabular}{|c|c|c|c|c|c|c|c|c|c|c|c|c|}
\hline & \multicolumn{12}{|c|}{ Year 1990} \\
\hline \multirow{12}{*}{ Year 1984} & Classes & $\mathbf{A}$ & B & $\mathrm{C}$ & D & $\mathbf{E}$ & $\mathbf{F}$ & $\mathbf{G}$ & $\mathbf{H}$ & I & $\mathbf{J}$ & Total \\
\hline & $\mathrm{A}$ & 2,68 & 0,24 & 0,01 & 0,04 & - & - & 0,47 & 0,01 & - & - & 3,45 \\
\hline & B & 0,82 & 6,34 & 2,08 & 0,16 & 0,03 & - & 0,88 & 0,44 & 0,04 & 0,01 & 10,80 \\
\hline & $\mathrm{C}$ & 0,02 & 1,52 & 9,03 & 0,93 & - & - & 0,93 & 0,45 & 0,02 & 0,00 & 12,90 \\
\hline & D & 0,28 & 0,35 & 0,31 & 33,62 & 0,09 & 2,25 & 0,42 & 1,35 & 0,08 & 4,98 & 43,73 \\
\hline & $\mathrm{E}$ & 0,00 & 0,07 & 0,03 & 0,10 & 0,00 & 0,00 & 0,02 & 0,01 & - & - & 0,23 \\
\hline & $\mathrm{F}$ & - & - & - & 1,07 & 0,04 & 2,65 & - & 0,01 & - & 0,35 & 4,12 \\
\hline & G & 0,31 & 0,33 & 0,58 & 0,13 & 0,00 & - & 3,45 & 0,01 & - & 0,01 & 4,82 \\
\hline & $\mathrm{H}$ & 0,12 & 1,76 & 2,19 & 5,87 & 0,01 & 0,00 & 0,97 & 1,64 & 0,07 & 0,06 & 12,69 \\
\hline & I & - & 0,13 & 0,02 & - & - & - & - & 0,00 & 0,09 & - & 0,24 \\
\hline & $\mathrm{J}$ & 0,13 & 0,03 & 0,06 & 3,25 & 0,06 & 1,01 & 0,15 & 0,17 & 0,01 & 2,17 & 7,04 \\
\hline & Total & 4,36 & 10,77 & 14,31 & 45,17 & 0,23 & 5,91 & 7,29 & 4,09 & 0,31 & 7,58 & 100 \\
\hline
\end{tabular}

A: Water bodies B: Grassland savannah C: Hyphaene benguellensis forest D: Wooded savannah E: Burned areas F: Bare soils G: Aquatic vegetation H: Cultivated areas I: Dense forest relics, J: Built areas.

Table 3. Transition matrix in land cover between 1990 and 2000 (\%).

\begin{tabular}{|c|c|c|c|c|c|c|c|c|c|c|c|c|}
\hline & \multicolumn{12}{|c|}{ Year 2000} \\
\hline \multirow{12}{*}{ Year 1990} & Classes & $\mathbf{A}$ & B & $\mathrm{C}$ & D* & $\mathbf{E}$ & $\mathbf{F}$ & $\mathbf{G}$ & $\mathbf{H}$ & I & $\mathbf{J}$ & Total \\
\hline & A & 2,22 & 0,52 & 0,06 & 0,09 & 0,01 & 0,01 & 0,32 & 0,71 & - & 0,41 & 4,35 \\
\hline & B & 0,18 & 4,30 & 1,24 & 0,63 & 0,78 & 0,03 & 0,39 & 3,12 & 0,00 & 0,11 & 10,78 \\
\hline & $\mathrm{C}$ & 0,01 & 1,52 & 4,43 & 0,15 & 0,60 & 0,00 & 4,23 & 3,23 & 0,00 & 0,14 & 14,31 \\
\hline & $\mathrm{D}$ & 0,02 & 0,10 & 0,72 & $2,23 *$ & 6,60 & 4,57 & 1,85 & 26,94 & - & 2,12 & 45,15 \\
\hline & $\mathrm{E}$ & 0,00 & 0,00 & - & 0,00 & 0,05 & 0,13 & 0,01 & 0,01 & - & 0,02 & 0,22 \\
\hline & $\mathrm{F}$ & - & - & - & 0,07 & 0,41 & 4,77 & 0,01 & 0,55 & - & 0,11 & 5,92 \\
\hline & G & 0,08 & 0,74 & 1,02 & 0,27 & 0,12 & 0,02 & 3,21 & 1,64 & - & 0,19 & 7,29 \\
\hline & $\mathrm{H}$ & 0,00 & 0,04 & 0,07 & 0,96 & 0,36 & 0,38 & 0,09 & 1,97 & 0,00 & 0,18 & 4,05 \\
\hline & I & - & 0,00 & - & 0,03 & 0,03 & 0,06 & 0,00 & 0,08 & $*$ & 0,02 & 0,22 \\
\hline & $\mathbf{J}$ & 0,05 & 0,02 & 0,01 & 0,27 & 1,01 & 1,61 & 0,03 & 3,29 & - & 1,38 & 7,67 \\
\hline & Total & 2,56 & 7,24 & 7,55 & 2,47 & 9,97 & 11,58 & 10,14 & 41,54 & 0,00 & 4,68 & 100 \\
\hline
\end{tabular}

A: Water bodies B: Grassland savannah C: Hyphaene benguellensis forest D: Wooded savannah D*: Shrub savannah E: Burned areas F: Bare soils G: Aquatic vegetation H: Cultivated areas I*: No common patches for year 1990 and 2000 images, J: Built areas. N. B: Wooded savannah disappearance and shrub savannah appearance in 2000. 
Between 1990 and 2000, the most important land cover area transfers were conversion of grassland savannah into cultivated areas (3.12\%), modification of Hyphaene benguellensis forest in aquatic vegetation (4.23\%), conversion of Hyphaene benguellensis forest into cultivated areas $(3.23 \%)$, conversion of wooded savannah into burned areas $(6.60 \%)$, bare soils $(4.57 \%)$, cultivated areas $(26.94 \%)$ and built-up areas $(2.12 \%)$ and conversion of built-up areas into cultivated areas $(3.29 \%)$ (Table 3$)$. The most stable land cover classes are bare soils (4.77\%), Hyphaene benguellensis forest $(4.43 \%)$, grassland savannah $(4.30 \%)$, aquatic vegetation $(3.21 \% \%)$ and water bodies $(2.22 \%)$ which make $82 \%$ of the overall stability representing $23 \%$ of the park (Table 3, Figure 7), i.e. 2385 ha. Changes resulted in a $61.8 \%$ decrease of the vegetation cover from 8312 ha to 3172 ha. The quantitative loss of the vegetation cover was mainly due to the disappearance of the wooded savannah, a near disappearance of dense forest relics narrowed by $98 \%$ and a decrease of Hyphaene benguellensis forest whose area moved from 1530 ha to 807 ha; i.e. $47.2 \%$ decrease. Changes also resulted in a $278.9 \%$ increase of anthropized areas from 1912 ha to 7244 ha Cultivated and burned areas were the most extensive classes. Their areas increased from 436 ha to 4441 ha and from 24 ha to 1064 ha; i.e. $91.9 \%$ and $428.1 \%$.
Between 2000 and 2011, considerable land cover area transfers were modification of grassland savannah in Hyphaene benguellensis forest $(2.04 \%)$, conversion of burned areas into shrub savannah $(3.51 \%)$, cultivated areas $(3,01 \%)$ and built-up areas $(2.40 \%)$, conversion of bare soils into shrub savannah $(4.71 \%)$ and built-up areas (2.84\%), modification of aquatic vegetation in Hyphaene benguellensis forest (4.68\%) and conversion of cultivated areas into Hyphaene benguellensis forest $(4.65 \%)$, shrub savannah $(14.87 \%)$ and built-up areas $(2.15 \%)$ (Table 4$)$. The most stable land cover classes are cultivated areas (15.34\%), Hyphaene benguellensis forest $(5.05 \%)$, grassland savannah $(3.33 \%)$, bare soils $(3.09 \%)$ and aquatic vegetation $(2.60 \%)$, which accounts for $84 \%$ of the overall stability representing $35 \%$ of the park (Table 4 , Figure 8 ); i.e. 3751 ha. The changes resulted in an extension of $83.8 \%$ of the vegetation cover from 3172 ha to 5832 ha. The quantitative gains of vegetation are mainly due to the extension of the shrub savannah and the Hyphaene benguellensis forest whose areas have increased from 504 ha to 2869 ha and from 807 ha to 1801 ha; i.e. $469.7 \%$ and $123.1 \%$ increases. Conversely, changes resulted in a decline in anthropized zones which lost $37.5 \%$ of their area from 7244 ha to 4524 ha. Burned areas, bare soils and cultivated areas declined the most, losing $61.9 \%, 58.5 \%$ and $40.8 \%$ of their surfaces.

Table 4. Transition matrix in land cover between 2000 and $2011(\%)$.

\begin{tabular}{|c|c|c|c|c|c|c|c|c|c|c|c|c|}
\hline & \multicolumn{12}{|c|}{ Year 2011} \\
\hline \multirow{12}{*}{ Year 2000} & Classes & $\mathbf{A}$ & B & $\mathbf{C}$ & D* & $\mathbf{E}$ & $\mathbf{F}$ & $\mathbf{G}$ & $\mathbf{H}$ & I & $\mathbf{J}$ & Total \\
\hline & A & 2,09 & 0,22 & 0,08 & 0,00 & 0,00 & - & 0,14 & 0,00 & - & 0,02 & 2,55 \\
\hline & B & 0,35 & 3,33 & 2,04 & 0,12 & 0,22 & - & 0,16 & 1,00 & - & 0,04 & 7,26 \\
\hline & $\mathrm{C}$ & 0,05 & 0,49 & 5,05 & 0,21 & 0,15 & 0,02 & 0,79 & 0,76 & - & 0,04 & 7,56 \\
\hline & $\mathrm{D}^{*}$ & 0,04 & 0,29 & 0,11 & 1,77 & 0,10 & 0,23 & 0,00 & 1,83 & - & 0,34 & 4,71 \\
\hline & $\mathrm{E}$ & 0,01 & 0,06 & 0,11 & 3,51 & 0,62 & 0,23 & 0,01 & 3,01 & - & 2,40 & 9,96 \\
\hline & $\mathrm{F}$ & 0,00 & 0,03 & 0,01 & 4,71 & 0,38 & 3,09 & - & 0,52 & - & 2,84 & 11,58 \\
\hline & G & 0,23 & 0,40 & 4,68 & 0,27 & 0,50 & 0,03 & 2,60 & 1,34 & - & 0,10 & 10,15 \\
\hline & $\mathrm{H}$ & 0,30 & 1,59 & 4,65 & 14,87 & 1,68 & 0,68 & 0,28 & 15,34 & - & 2,15 & 41,54 \\
\hline & I & - & - & - & 0,00 & - & - & - & 0,00 & $* *$ & 0,00 & 0,00 \\
\hline & $\mathrm{J}$ & 0,05 & 0,45 & 0,13 & 1,37 & 0,14 & 0,52 & 0,02 & 0,80 & - & 1,21 & 4,69 \\
\hline & Total & 3,12 & 6,86 & 16,86 & 26,83 & 3,79 & 4,80 & 4,00 & 24,60 & - & 9,14 & 100 \\
\hline
\end{tabular}

A: Water bodies B: Grassland savannah C: Hyphaene benguellensis forest D*: Shrub savannah E: Burned areas F: Bare soils G: Aquatic vegetation H: Cultivated areas I**: Dense forest disappearance J: Built areas.

Table 5. Transition matrix in land cover between 2011 and 2015 (\%).

\begin{tabular}{|c|c|c|c|c|c|c|c|c|c|c|c|c|}
\hline & \multicolumn{12}{|c|}{ Year 2015} \\
\hline \multirow{12}{*}{$\begin{array}{l}\text { Year } \\
2011\end{array}$} & Classes & $\mathbf{A}$ & B & $\mathrm{C}$ & D* & $\mathbf{E}$ & $\mathbf{F}$ & G & $\mathbf{H}$ & I & $\mathbf{J}$ & Total \\
\hline & $\mathrm{A}$ & 2,05 & 0,20 & 0,04 & 0,00 & 0,27 & - & 0,13 & 0,34 & & 0,09 & 3,12 \\
\hline & B & 0,06 & 4,29 & 0,15 & 0,15 & 0,11 & 0,09 & 0,30 & 1,64 & & 0,09 & 6,88 \\
\hline & $\mathrm{C}$ & 0,05 & 1,65 & 8,67 & 0,50 & 1,73 & 0,00 & 1,65 & 2,58 & & 0,01 & 16,84 \\
\hline & $\mathrm{D}^{*}$ & 0,01 & 0,30 & 0,01 & 12,59 & 3,17 & 0,90 & 0,02 & 8,88 & & 0,97 & 26,85 \\
\hline & $\mathrm{E}$ & 0,02 & 0,26 & 0,67 & 0,37 & 1,50 & 0,17 & 0,17 & 0,47 & & 0,16 & 3,79 \\
\hline & $\mathrm{F}$ & 0,00 & 0,00 & - & 1,62 & 0,26 & 1,17 & 0,00 & 1,31 & & 0,44 & 4,80 \\
\hline & G & 0,22 & 0,26 & 0,83 & 0,01 & 0,36 & - & 2,25 & 0,08 & & - & 4,01 \\
\hline & $\mathrm{H}$ & 0,01 & 2,25 & 0,25 & 6,56 & 6,88 & 0,07 & 0,39 & 8,10 & & 0,09 & 24,60 \\
\hline & I & & & & & & & & & $* *$ & & \\
\hline & $\mathrm{J}$ & 0,02 & 0,17 & 0,02 & 4,03 & 1,05 & 0,79 & 0,00 & 1,98 & & 1,08 & 9,14 \\
\hline & Total & 2,44 & 9,38 & 10,64 & 25,83 & 15,33 & 3,19 & 4,91 & 25,38 & & 2,93 & 100 \\
\hline
\end{tabular}

A: Water bodies B: Grassland savannah C: Hyphaene benguellensis forest D*: Shrub savannah E: Burned areas F: Bare soils G: Aquatic vegetation H: Cultivated areas I**: Dense forest disappearance J: Built areas. 
From 2011 to 2015, the most significant land cover area transfers are conversion of Hyphaene benguellensis forest into cultivated areas $(2.58 \%)$, conversion of shrub savannah into burned areas (3.17\%) and cultivated areas ( $8.88 \%)$, conversion of cultivated areas into grassland savannah $(2.25 \%)$, shrub savannah $(6.56 \%)$ and burned areas $(6.88 \%)$ and conversion of built-up areas into shrub savannah (4.03\%) and cultivated areas $(1.98 \%)$ (Table 5). The most stable land cover classes are shrub savannah (12.59\%), Hyphaene benguellensis forest (8.67\%), cultivated areas $(8.10 \%)$ and grassland savannah $(4.29 \% \%)$ which represent $80 \%$ of the overall stability set at $42 \%$ of the park (Table 5 , Figure 9); i.e. 4456 ha. The changes recorded reduced the vegetation cover by $6.9 \%$ from 5832 ha to 5425 ha. The decline of the vegetation cover mainly affected Hyphaene benguellensis forest, whose area decreased from 1801 ha to 1135 ha; representing a $36.9 \%$ reduction. These changes have increased the anthropized zones by $10.6 \%$ from 4524 ha to 5004 ha. Burned areas extended the most from 405 ha to 1639 ha; which corresponds to a $304.8 \%$ increase.

During the overall study period (1984-2015), the most remarkable land cover area transfers are conversion of grassland savannah into cultivated areas (1.81\%), conversion of wooded savannah into burned areas $(8.96 \%)$ and cultivated areas $(13.93 \%)$, conversion of cultivated areas into shrub savannah $(1.98 \%)$ and burned areas $(2.77 \%)$ and conversion of built-up areas into shrub savannah (3.27\%) (Table 6). The most stable land cover classes are Hyphaene benguellensis forest (7.29\%), grassland savannah $(5.88 \%)$, cultivated areas $(4.58 \%)$ and aquatic vegetation $(2.01 \%)$ which represent $85 \%$ of the overall stability set at $23 \%$ of the park (Table 6, Figure 11); i.e. 2500 ha. Changes resulted in a $29.9 \%$ decline in the vegetation cover from 7738 ha to 5425 ha and a $94.5 \%$ extension of the anthropized zones from 2573 ha to 5004 ha. Meanwhile, the park's water coverage has decreased by $31.2 \%$ since its area has decreased from 378 ha to 260 ha. On one hand, the decline in vegetation cover was mainly due to the disappearance of the wooded savannah and the dense forest relics. On the other hand, it comes from the decrease of Hyphaene benguellensis forest and the grassland savannah. The extension of anthropogenic zones was mainly due to the development of burned areas and cultivated areas which have increased from 24 ha to 1639 ha and from 1357 ha to 2711 ha; representing $6729.1 \%$ and $99.7 \%$ increases.

Table 6. Transition matrix in land cover between 1984 and 2015 (\%).

\begin{tabular}{|c|c|c|c|c|c|c|c|c|c|c|c|c|}
\hline & \multicolumn{12}{|c|}{ Year 2015} \\
\hline \multirow{12}{*}{ Year 1984} & Classes & A & B & C & $D^{*}$ & $\mathbf{E}$ & $\mathbf{F}$ & $\mathbf{G}$ & H & I & $\mathbf{J}$ & Total \\
\hline & A & 1,51 & 0,63 & 0,22 & 0,02 & 0,24 & 0,00 & 0,31 & 0,53 & & 0,06 & 3,52 \\
\hline & B & 0,38 & 5,88 & 0,86 & 0,14 & 0,59 & 0,02 & 1,09 & 1,81 & & 0,03 & 10,80 \\
\hline & $\mathrm{C}$ & 0,03 & 0,80 & 7,29 & 0,66 & 1,57 & - & 0,91 & 1,64 & & 0,01 & 12,91 \\
\hline & D & 0,02 & 0,21 & 0,22 & 17,92 & 8,96 & 0,97 & 0,07 & 13,93 & & 1,42 & 43,72 \\
\hline & $\mathrm{E}$ & 0,00 & 0,05 & 0,00 & 0,03 & 0,02 & - & 0,01 & 0,11 & & - & 0,22 \\
\hline & $\mathrm{F}$ & 0,00 & 0,00 & - & 1,66 & 0,03 & 1,36 & - & 0,73 & & 0,33 & 4,11 \\
\hline & G & 0,31 & 0,53 & 0,77 & 0,15 & 0,66 & 0,01 & 2,01 & 0,35 & & 0,02 & 4,81 \\
\hline & $\mathrm{H}$ & 0,14 & 1,12 & 1,26 & 1,98 & 2,77 & 0,04 & 0,48 & 4,58 & & 0,32 & 12,69 \\
\hline & I & 0,01 & 0,09 & 0,00 & - & 0,01 & - & 0,02 & 0,02 & $* *$ & - & 0,15 \\
\hline & $\mathrm{J}$ & 0,03 & 0,07 & 0,00 & 3,27 & 0,48 & 0,80 & 0,01 & 1,64 & & 0,73 & 7,03 \\
\hline & Total & 2,43 & 9,38 & 10,62 & 25,83 & 15,33 & 3,20 & 4,91 & 25,34 & & 2,92 & 100 \\
\hline
\end{tabular}

A: Water bodies B: Grassland savannah C: Hyphaene benguellensis forest D: Wooded savannah D*: Shrub savannah E: Burned areas F: Bare soils G: Aquatic vegetation H: Cultivated areas I**: Dense forest disappearance J: Built areas.

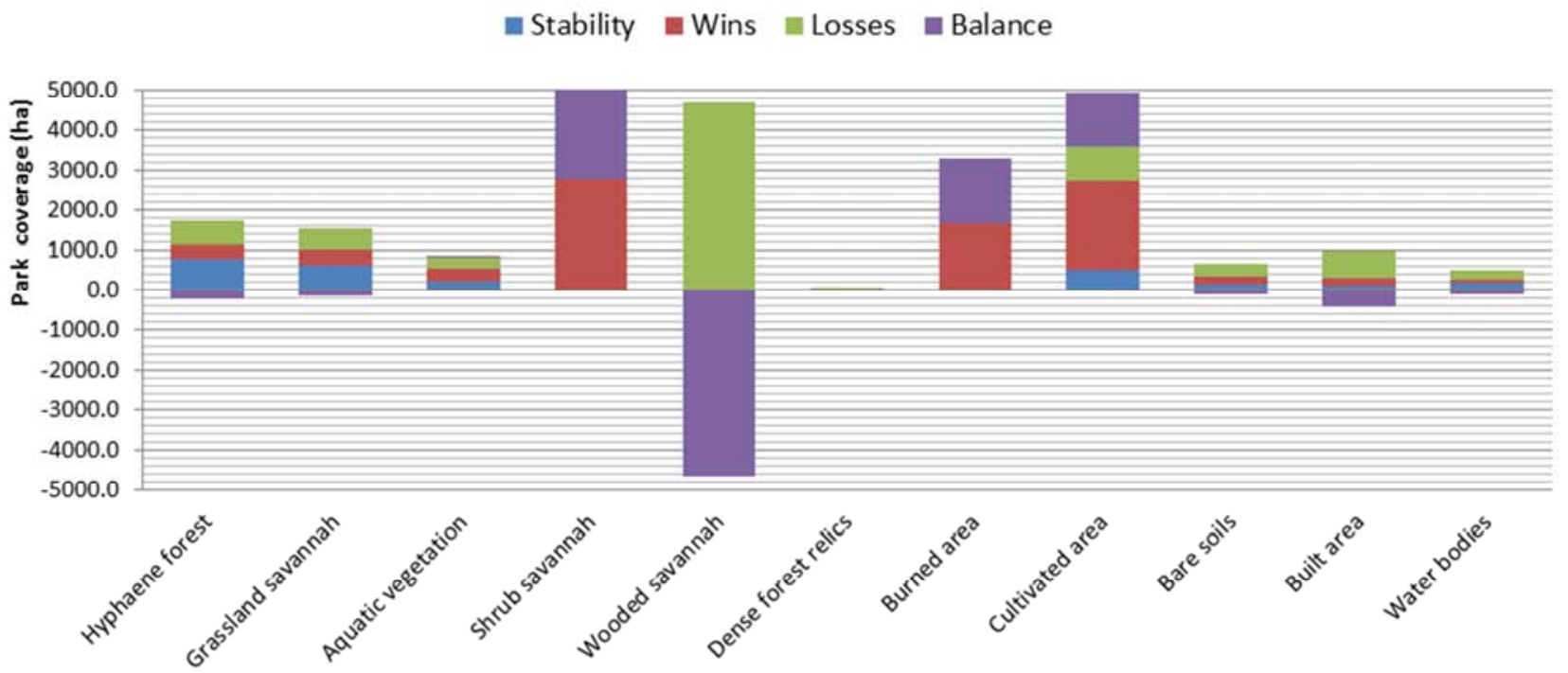

Figure 5. Overall balance sheets of land cover classes between 1984 and 2015. 
As shown in figure 5 , the land cover classes with a negative balance are mainly wooded savannah and dense forest relics that have completely disappeared from the landscape. It's also the case of built-up areas, Hyphaene benguellensis forest and grassland savannah which lost 437 ha, 244 ha and 151 ha. Those with a positive balance are essentially shrub savannah that appeared in the landscape. It is also the case of burned areas and cultivated areas whose areas expanded from 1614 ha to $1354 \mathrm{ha}$. These trends are largely negative and incompatible with the conservation objectives of the park.

Figures 6, 7, 8, 9 and 11 give periodical synthetic landscape and vegetation dynamics which characterized the Rusizi Park between 1984 and 2015. As mentioned above, the progression of vegetation is composed of quantitative and qualitative gains of vegetation while the regression of vegetation is made of quantitative and qualitative losses of vegetation. Figures 7 and 8 show that the periods 1990-2000 and 2000-2011 were respectively characterized by high and low levels of vegetation regression. Between 1990 and 2000, quite the whole park was affected by vegetation regression. From year 2000, we note that anthropized zones and neutral conversions are particularly important (Figures 8-9). These evolutions resulted in a high level of vegetation regression from 1984 to 2015 (Figure 11). The middle southeastern part of the park is particularly affected by the destruction of vegetation (Figures 7-11).

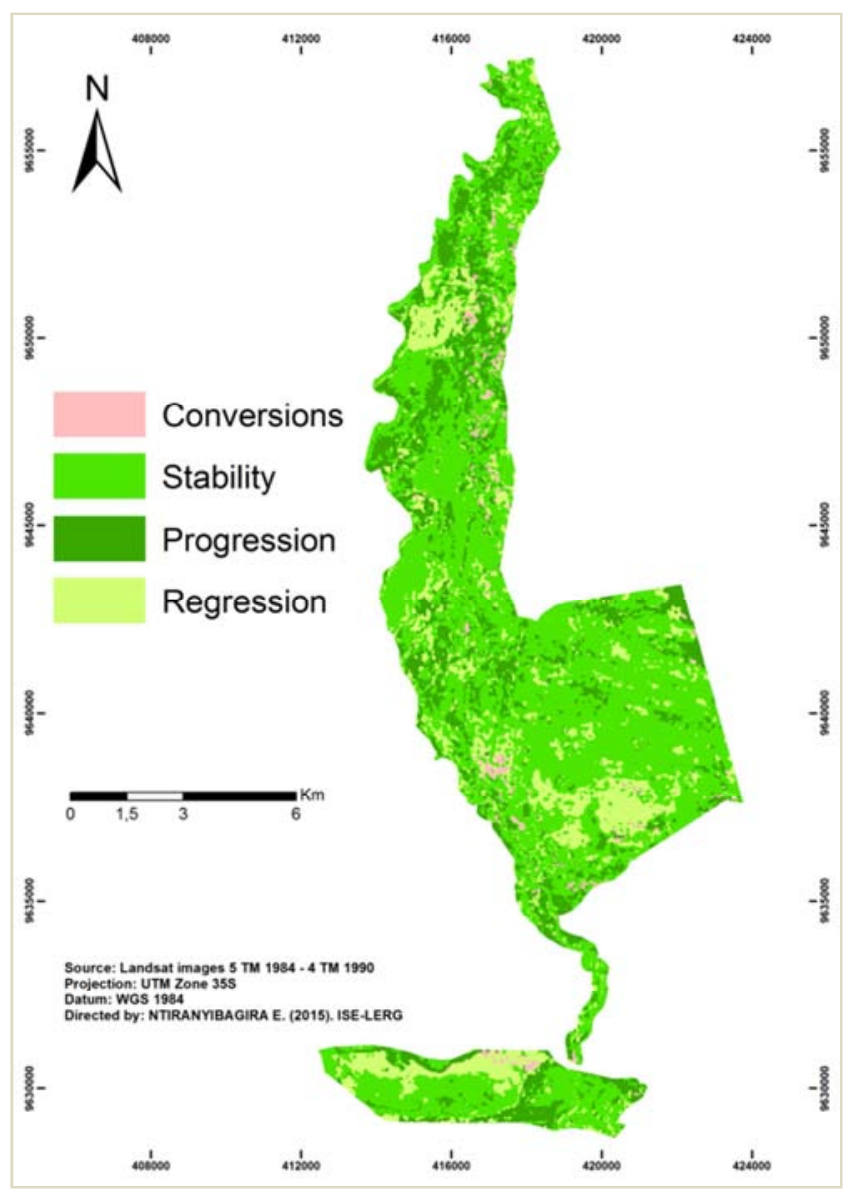

Figure 6. Land cover changes (1984-1990).

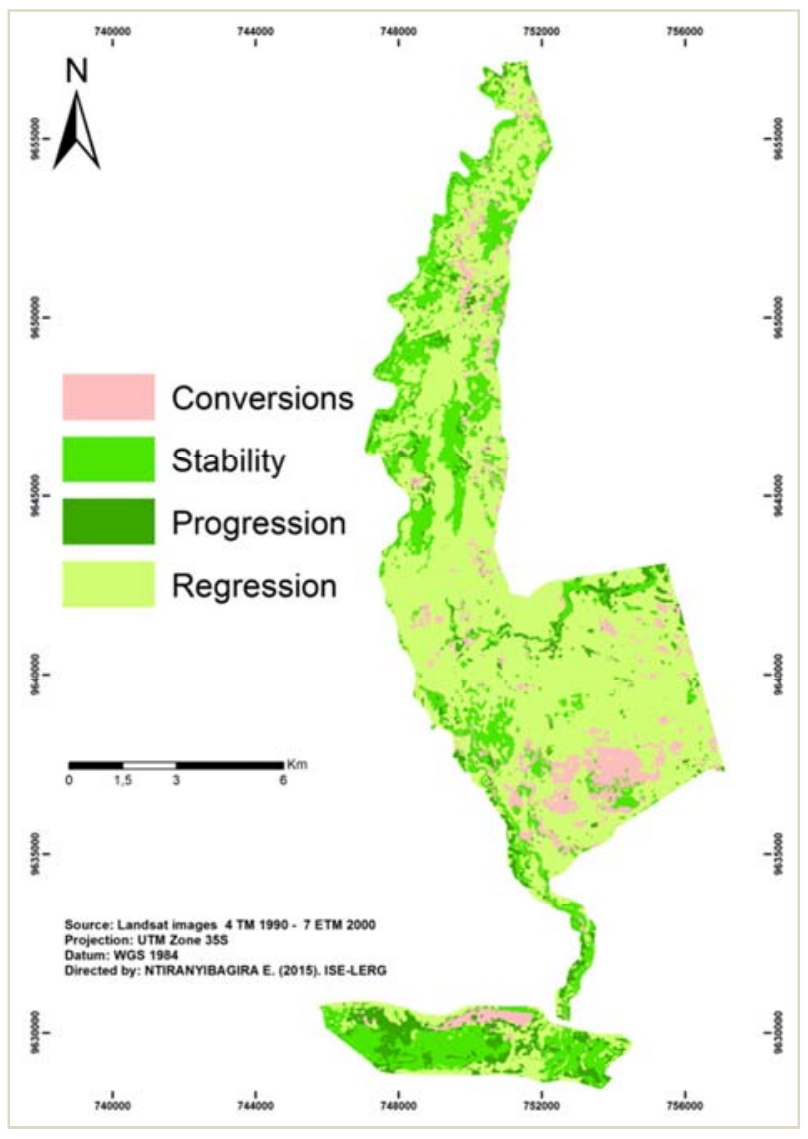

Figure 7. Land cover changes (1990-2000).

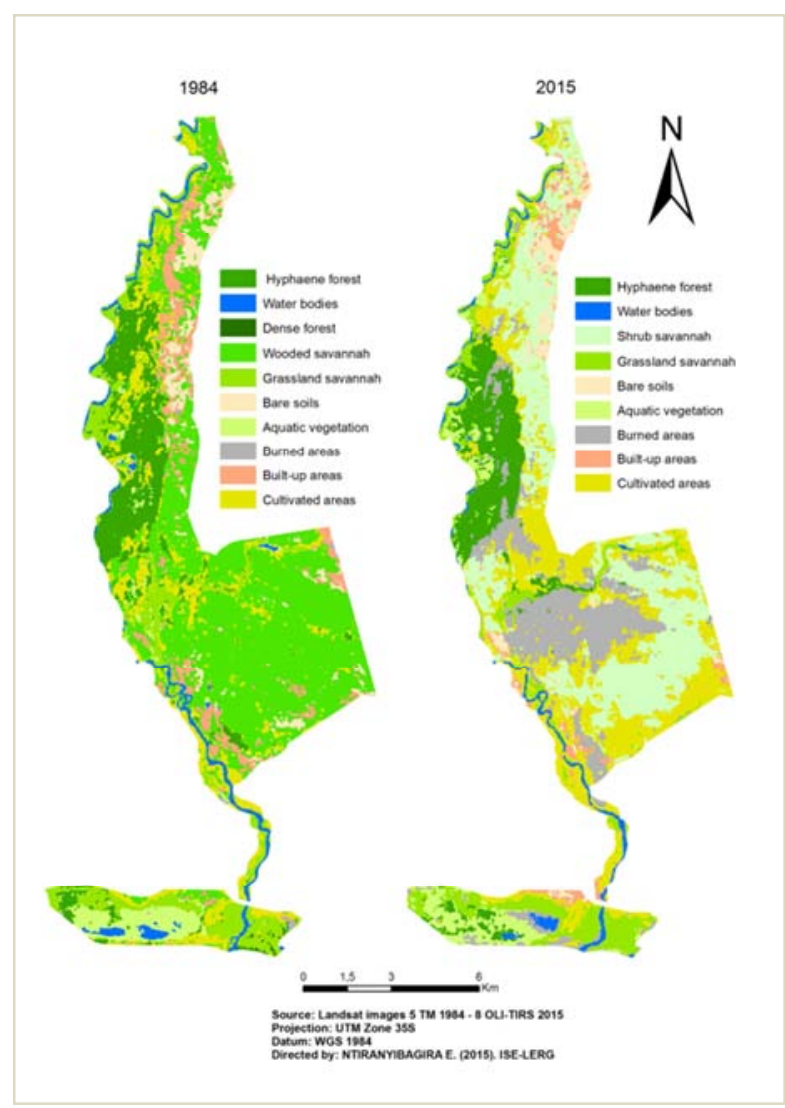

Figure 8. Land cover changes (2000-2011). 


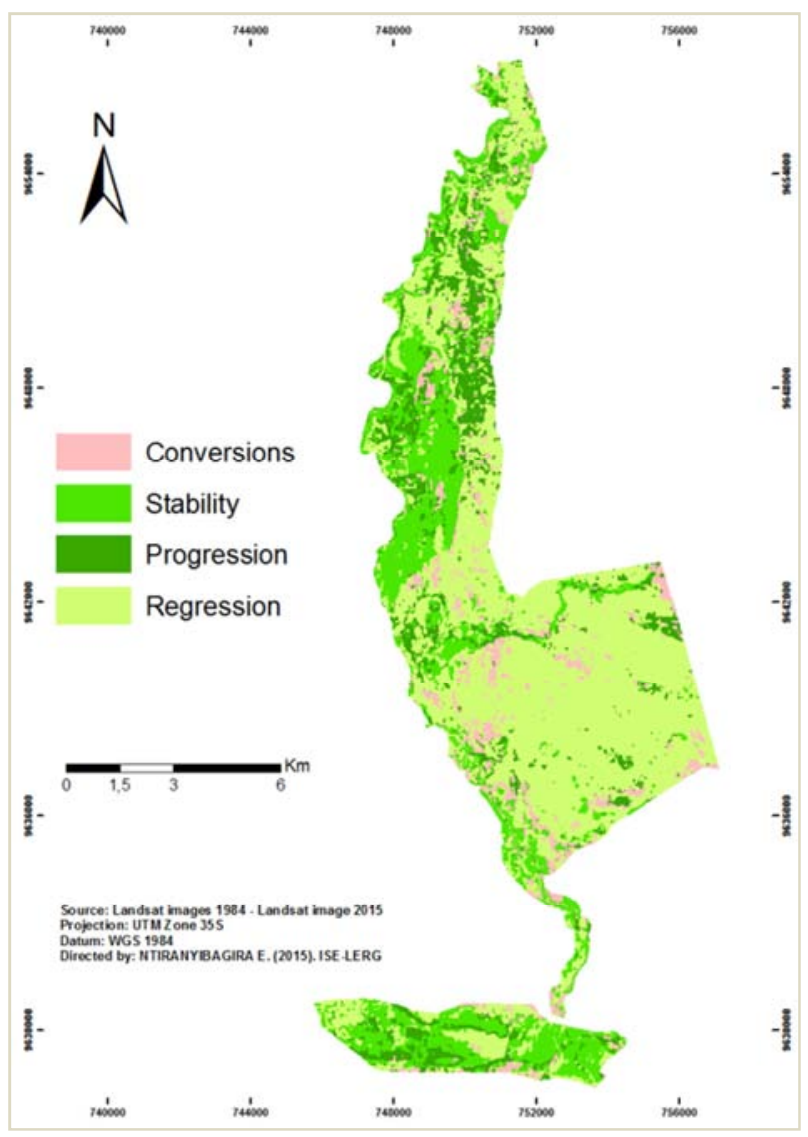

Figure 9. Land cover changes (2011-2015).

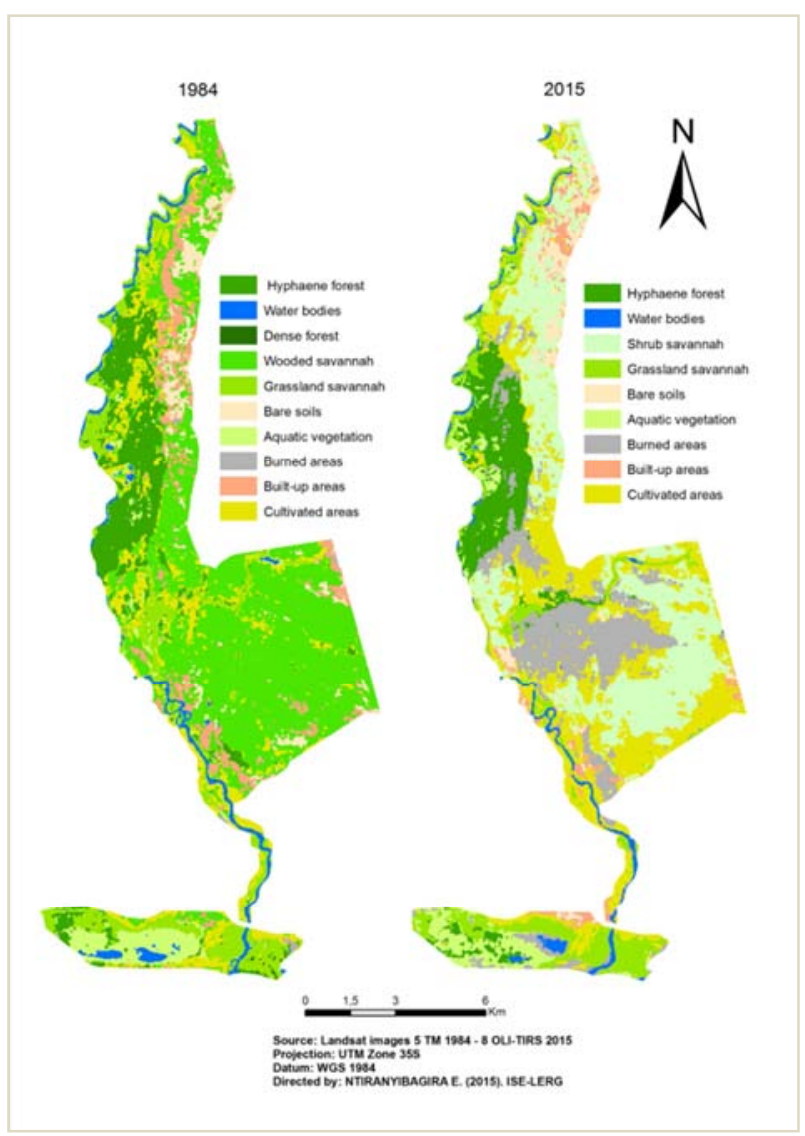

Figure 10. Land cover classes in 1984 and 2015.

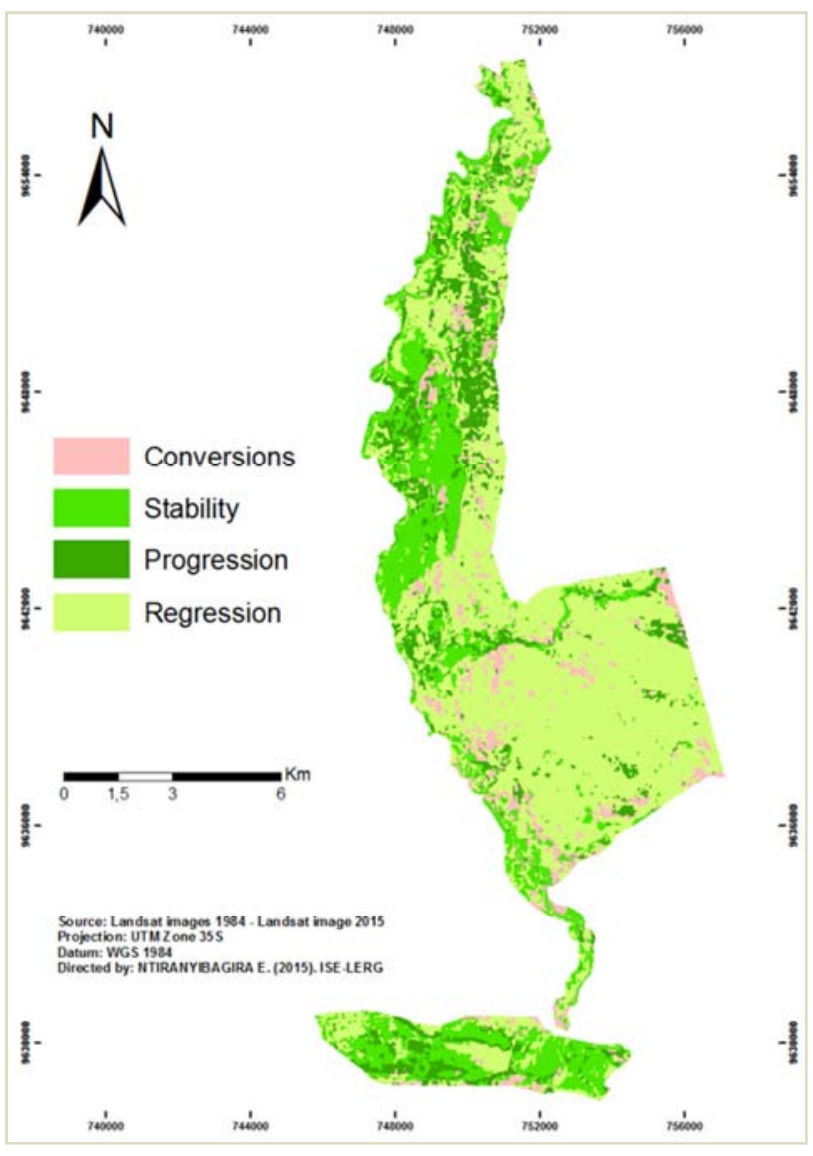

Figure 11. Land cover changes (1984-2015).

\subsection{Change and Evolution Indicators}

\subsubsection{Spatial Indices and Processes}

The results obtained on the spatial structure indices and derived spatial transformation processes of the land cover classes are presented in Table 7. They showed a great variability of spatial processes which demonstrate the existence of deep changes in the park's land cover.

In total, six spatial transformation processes on the ten geometries that are theoretically possible have been counted. These include patch creation, attrition, fragmentation, dissection, aggregation and enlargement which affect differently land cover classes over time (Figure 12). Between 1984 and 2015, the number of classes affected by patch creation decreases while the number of classes affected by patch attrition is increasing (Figure 12).

By analyzing the typology of spatial transformation processes that affect land over classes, there are notable differences that determine their specific evolution. Built-up areas and water bodies were affected by 4 types of spatial processes. Grassland savannah, Hyphaene benguellensis forest, aquatic vegetation, burned areas, cultivated areas and wooded savannah were affected by 3 types of spatial processes. Dense forest relics, shrub savannah and bare soils were affected by only 2 types of spatial processes (Figure 13).

The most frequent spatial transformation processes are patch attrition and creation that account for $37 \%$ and $29 \%$ of 
situations, respectively. The rare observed spatial processes are patch enlargement and fragmentation that account for only $2 \%$ and $4 \%$ of the cases (Figure 13 ). Patch creation is affecting all the land cover classes, except grassland savannah, wooded savannah and dense forest relics while burned areas are the unique land cover class to be not affected by patch attrition (Figure 13).

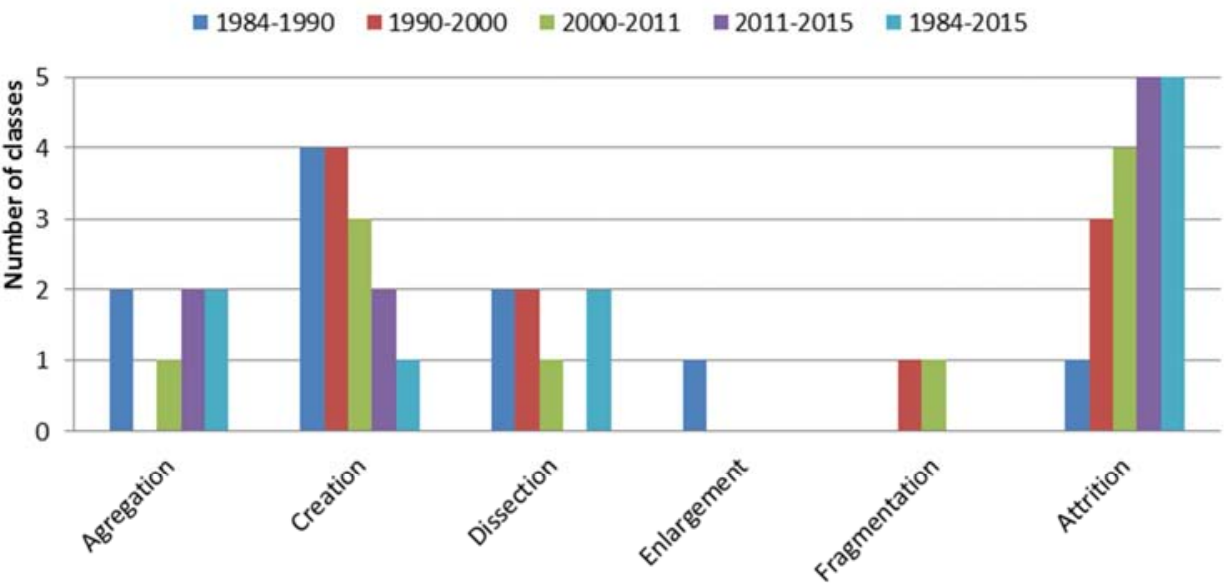

Figure 12. Typology and evolution of spatial transformation processes from 1984 to 2015.

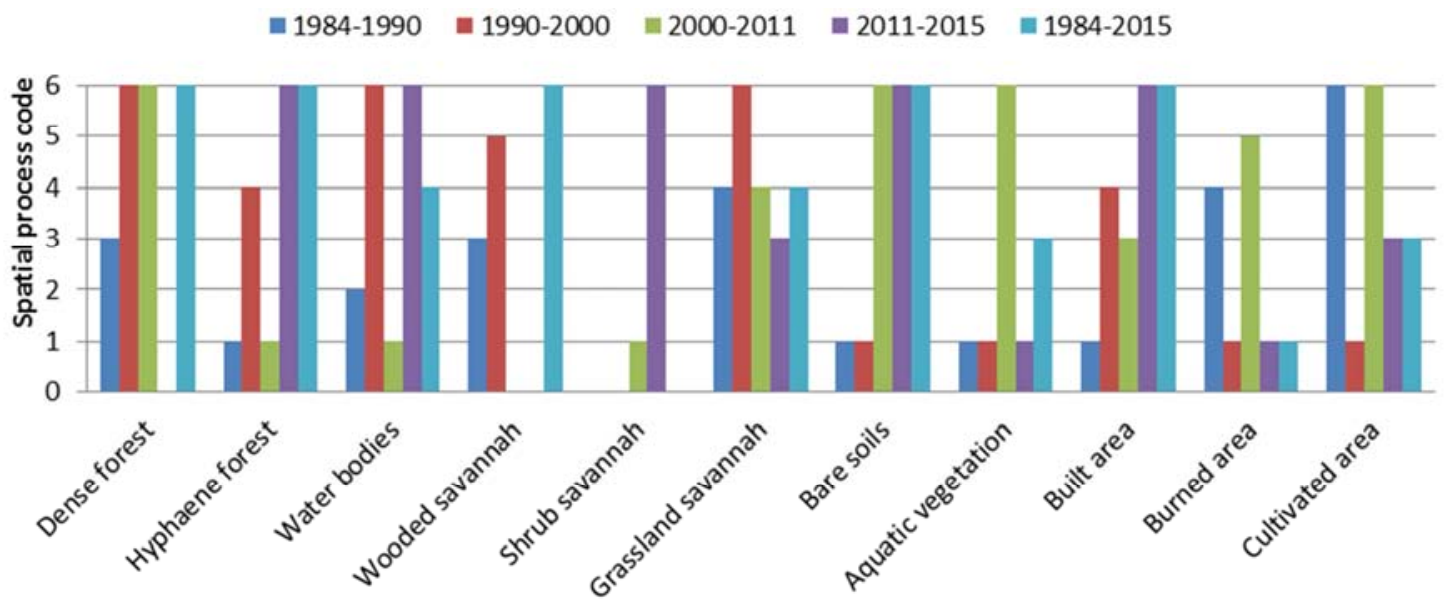

Spatial processes codes: 1. Creation, 2. Enlargement, 3. Agregation, 4. Dissection, 5. Fragmentation, 6. Attrition

Figure 13. Evolution of the spatial transformation processes affecting land cover classes from 1984 to 2015.

Table 7. Spatial structure indices of land cover classes between 1984 and 2015.

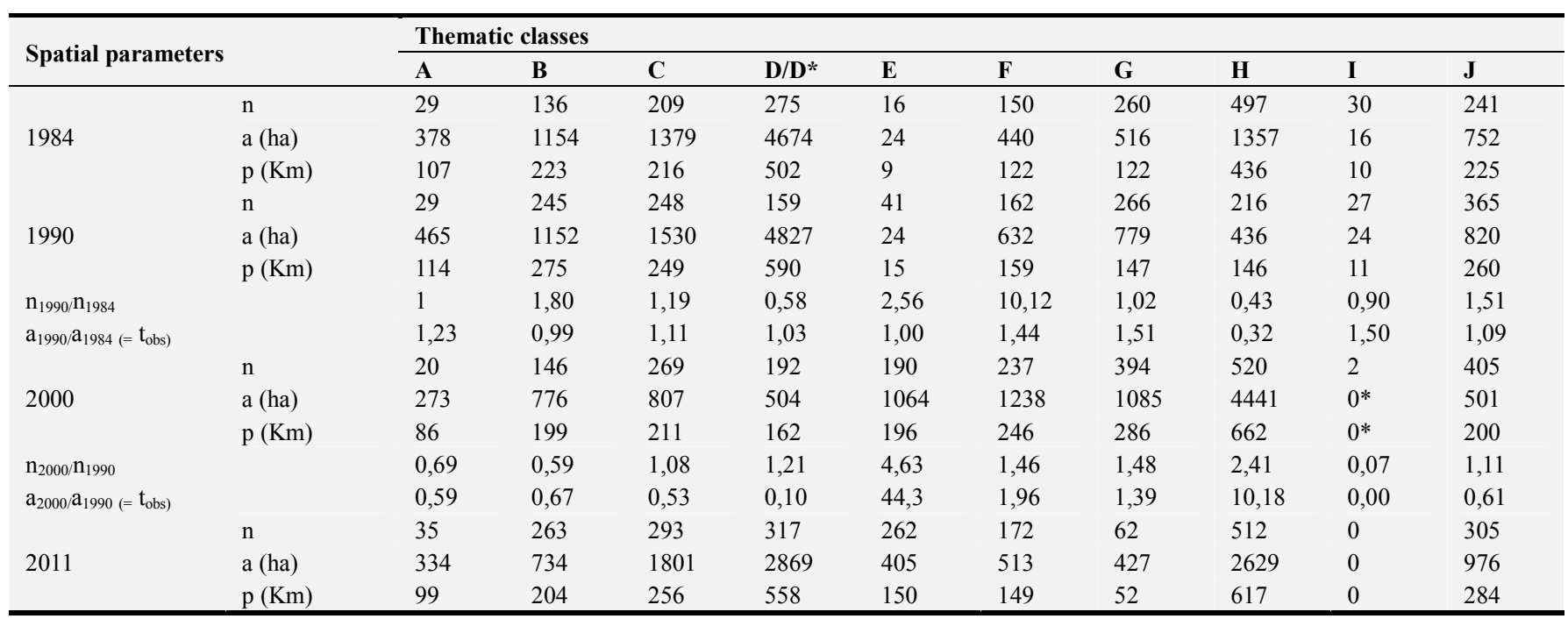




\begin{tabular}{|c|c|c|c|c|c|c|c|c|c|c|c|}
\hline \multirow{2}{*}{\multicolumn{2}{|c|}{ Spatial parameters }} & \multicolumn{10}{|c|}{ Thematic classes } \\
\hline & & \multirow{2}{*}{$\begin{array}{l}\mathbf{A} \\
1,75\end{array}$} & & \multirow{2}{*}{$\begin{array}{l}\mathbf{C} \\
1,09\end{array}$} & \multirow{2}{*}{$\begin{array}{l}\mathbf{D} / \mathbf{D}^{*} \\
1,65\end{array}$} & \multirow{2}{*}{$\begin{array}{l}\mathbf{E} \\
1,38\end{array}$} & & \multirow{2}{*}{$\begin{array}{l}\mathbf{G} \\
0,16\end{array}$} & \multirow{2}{*}{$\begin{array}{l}\mathbf{H} \\
0,98\end{array}$} & \multirow{2}{*}{$\begin{array}{l}\mathbf{I} \\
0,00\end{array}$} & \multirow{2}{*}{$\begin{array}{l}\mathbf{J} \\
0,75\end{array}$} \\
\hline $\mathrm{n}_{2011 / \mathrm{n}_{2000}}$ & & & & & & & & & & & \\
\hline $\mathrm{a}_{2011} \mathrm{a}_{2000}\left(=\mathrm{t}_{\mathrm{obs}}\right)$ & & 1,22 & 0,95 & 2,23 & 5,69 & 0,38 & 0,41 & 0,39 & 0,59 & 0,00 & 1,95 \\
\hline & $\mathrm{n}$ & 31 & 148 & 96 & 166 & 271 & 93 & 157 & 399 & 0 & 179 \\
\hline \multirow[t]{2}{*}{2015} & a (ha) & 260 & 1003 & 1136 & 2761 & 1639 & 342 & 525 & 2711 & 0 & 313 \\
\hline & $\mathrm{p}(\mathrm{Km})$ & 85 & 206 & 143 & 327 & 255 & 89 & 132 & 529 & 0 & 123 \\
\hline $\mathrm{n}_{2015} \mathrm{n}_{2011}$ & & 0,89 & 0,56 & 0,33 & 0,52 & 4,37 & 0,54 & 2,53 & 0,78 & N.A & 0,59 \\
\hline $\mathrm{a}_{2015} \mathrm{a}_{2011}\left(=\mathrm{t}_{\mathrm{obs}}\right)$ & & 0,78 & 1,37 & 0,63 & 0,96 & 4,05 & 0,67 & 1,23 & 1,03 & N.A & 0,32 \\
\hline $\mathrm{n}_{2015 / \mathrm{n}_{1984}}$ & & 1,07 & 1,09 & 0,46 & 0,60 & 16,94 & 0,62 & 0,60 & 0,80 & 0,00 & 0,74 \\
\hline $\left.\mathrm{a}_{2015 /} \mathrm{a}_{1984(=} \mathrm{t}_{\mathrm{obs}}\right)$ & & 0,69 & 0,87 & 0,82 & 0,59 & 68,29 & 0,78 & 1,02 & 1,99 & 0,00 & 0,42 \\
\hline
\end{tabular}

A: Water bodies B: Grassland savannah C: Hyphaene benguellensis forest D: Wooded savannah D*: Shrub savannah E: Burned areas F: Bare soils G: Aquatic vegetation H: Cultivated areas I: Dense forest relics J: Built areas $0^{*}$ : Very low or no significant values, N.A: Not Applicable.

Between 1984 and 1990, 5 types of spatial transformation processes were recorded. This is patch aggregation $\left(\mathrm{n}_{1990}<\mathrm{n}_{1984}, \mathrm{a}_{1990}>\mathrm{a}_{1984}\right)$ affecting dense forest relics and wooded savannah; patch creation $\left(\mathrm{n}_{1990}>\mathrm{n}_{1984}, \mathrm{a}_{1990}>\mathrm{a}_{1984}\right)$ affecting Hyphaene benguellensis forest, aquatic vegetation, built-up areas and bare soils; patch dissection $\left(\mathrm{n}_{1990}>\mathrm{n}_{1984}\right.$, $\mathrm{a}_{1990}<\mathrm{a}_{1984}$, tobs $\left.>0.5\right)$ affecting grassland savannah and burned areas; patch enlargement $\left(\mathrm{n}_{1990}=\mathrm{n}_{1984}, \mathrm{a}_{1990}>\mathrm{a}_{1984}\right)$ affecting water bodies and patch attrition $\left(\mathrm{n}_{1990}<\mathrm{n}_{1984}\right.$, $\mathrm{a}_{1990}<\mathrm{a}_{1984}$ ) affecting cultivated areas (Table 7). From 1990 to 2000, 4 types of spatial transformation processes were noted. This is patch attrition $\left(\mathrm{n}_{2000}<\mathrm{n}_{1990}, \quad \mathrm{a}_{2000}<\mathrm{a}_{1990}\right)$ affecting grassland savannah, dense forest relics and water bodies; patch dissection $\left(\mathrm{n}_{2000}>\mathrm{n}_{1990}, \mathrm{a}_{2000}<\mathrm{a}_{1990}, \mathrm{t}_{\mathrm{obs}}>0.5\right)$ affecting Hyphaene benguellensis forest and built-up areas; high patch fragmentation $\left(\mathrm{n}_{2000}>\mathrm{n}_{1990}, \mathrm{a}_{2000}<\mathrm{a}_{1990}, \mathrm{t}_{\mathrm{obs}}<<0.5\right)$ affecting wooded savannah which disappeared during the period and patch creation $\left(\mathrm{n}_{2000}>\mathrm{n}_{1990}, \mathrm{a}_{2000}>\mathrm{a}_{1990}\right)$ affecting aquatic vegetation, cultivated areas, burned areas and bare soils (Table 7). Between 2000 and 2011, 5 types of spatial transformation processes were observed. These include patch attrition $\left(\mathrm{n}_{2011}<\mathrm{n}_{2000}, \mathrm{a}_{2011}<\mathrm{a}_{2000}\right)$ affecting aquatic vegetation, dense forest relics that disappeared during the period, cultivated areas and bare soils; patch dissection $\left(\mathrm{n}_{2011}>\mathrm{n}_{2000}, \mathrm{a}_{2011}<\mathrm{a}_{2000}\right.$, $\left.\mathrm{t}_{\mathrm{obs}}>0.5\right)$ affecting grassland savannah; patch creation $\left(\mathrm{n}_{2011}>\mathrm{n}_{2000}, \mathrm{a}_{2011}>\mathrm{a}_{2000}\right)$ affecting shrub savannah, Hyphaene benguellensis forest and water bodies; patch fragmentation $\left(\mathrm{n}_{2011}>\mathrm{n}_{2000}, \mathrm{a}_{2011}<\mathrm{a}_{2000}, \mathrm{t}_{\mathrm{obs}}<0,5\right)$ affecting burned areas and patch aggregation $\left(\mathrm{n}_{2011}<\mathrm{n}_{2000}, \mathrm{a}_{2011}>\mathrm{a}_{2000}\right)$ affecting built-up areas (Table 7). From 2011 to 2015, 3 types of spatial transformation processes were observed. These include patch attrition $\left(\mathrm{n}_{2015}<\mathrm{n}_{2011}, \quad \mathrm{a}_{2015}<\mathrm{a}_{2011}\right)$ that affects Hyphaene benguellensis forest, shrub savannah, built-up areas, bare soils and water bodies; patch creation $\left(\mathrm{n}_{2015}>\mathrm{n}_{2011}, \mathrm{a}_{2015}>\mathrm{a}_{2011}\right)$ that affects aquatic vegetation and burned areas and patch aggregation $\left(\mathrm{n}_{2015}<\mathrm{n}_{2011}, \mathrm{a}_{2015}>\mathrm{a}_{2011}\right)$ which affects grassland savannah and cultivated areas (Table 7). Looking at the period 1984-2015 continuously, there are 4 types of spatial transformation processes. These are patch dissection $\left(\mathrm{n}_{2015}>\mathrm{n}_{1984}, \mathrm{a}_{2015}<\mathrm{a}_{1984}, \mathrm{t}_{\text {obs }}>0.5\right)$ affecting grassland savannah and water bodies; patch attrition $\left(\mathrm{n}_{2015}<\mathrm{n}_{1984}, \mathrm{a}_{2015}<\mathrm{a}_{1984}\right)$ affecting wooded savannah, Hyphaene benguellensis forest, dense forest relics, built-up areas and bare soils; patch aggregation $\quad\left(\mathrm{n}_{2015}<\mathrm{n}_{1984}, \quad \mathrm{a}_{2015}>\mathrm{a}_{1984}\right) \quad$ affecting aquatic vegetation and cultivated areas and patch creation $\left(\mathrm{n}_{2015}>\mathrm{n}_{1984}\right.$, $\mathrm{a}_{2015}>\mathrm{a}_{1984}$ ) affecting burned areas (Table 7).

\subsubsection{Dominance of Land Cover Classes}

The results on class dominance values and their evolution are presented in Table 8 . They show very contrasting trends between classes and periods.

In 1984, highly consolidated land cover classes were Hyphaene benguellensis forest (75.1\%), aquatic vegetation $(70.5 \%)$ and wooded savannah $(63.8 \%)$. The majority of land cover classes, namely cultivated areas $(12.5 \%)$, built-up areas (16.0\%), grassland savannah (16.6\%), bare soils $(16.6 \%)$ and dense forest relics (18.8\%) are highly fragmented (Table 8 ). The reference situation shows that the majority of the vegetation classes are still consolidated in large blocks while the anthropized zones are islets dispersed in the protected area. Figure 14 shows the dominance variations which affected land cover classes. Considering a threshold of $10 \%$, the most fragmenting class between 1984 and 1990 consisted of burned areas $(-29.2 \%)$. The most consolidating classes were cultivated areas $(+16.0 \%)$ and built-up areas $(+10.5 \%)$. From 1990 to 2000, the most fragmenting classes were Hyphaene benguellensis forest $(-45.0 \%)$, aquatic vegetation $(-40.4 \%)$, wooded savannah $(-30.5 \%)$ and built areas $(-11.9 \%)$. The most consolidating ones have been dense forest relics $(+54.2 \%)$, bare soils $(+36.5 \%)$, burned areas $(+28.3 \%)$ and cultivated areas (+23.8\%). Between 2000 and 2011, the most fragmenting classes were bare soils (-41.7\%) and burned areas $(-28.2 \%)$. The most consolidating ones were aquatic vegetation $(+60.3 \%)$, Hyphaene benguellensis forest $(+49.5 \%)$ and water bodies (+15.4\%). From 2011 to 2015, the land cover classes that were most fragmenting are aquatic vegetation $(-34.0 \%)$, water bodies $(-33.4 \%)$ and cultivated areas $(-12.5 \%)$. The most consolidating land cover classes were burnt areas $(+39.0 \%)$, shrub savannah $(+17.3 \%)$, grassland savannah $(+12.3 \%)$, Hyphaene benguellensis forest $(+10.5 \%)$ and bare soils $(+10.1 \%)$. Between 1984 and 2015, the land cover classes that were most fragmenting are water bodies $(-26.2 \%)$, wooded-shrub savannah $(-16.4 \%)$ and aquatic vegetation $(-13.2 \%)$. The most consolidating ones were cultivated areas $(+30.3 \%)$, grassland savannah $(+13.4 \%)$ and burned areas $(+10.0 \%)$. 
Table 8. Dominance values of land cover classes between 1984 and 2015.

\begin{tabular}{|c|c|c|c|c|c|c|c|c|c|c|c|}
\hline \multirow{2}{*}{\multicolumn{2}{|c|}{ Dominance parameters }} & \multicolumn{10}{|c|}{ Thematic classes } \\
\hline & & $\mathbf{A}$ & B & $\mathrm{C}$ & D/D* & $\mathbf{E}$ & $\mathbf{F}$ & $\mathbf{G}$ & $\mathbf{H}$ & I & $\mathbf{J}$ \\
\hline \multirow{3}{*}{1984} & $\mathrm{~A}_{\mathrm{m}}$ (ha) & 153 & 192 & 1035 & 2982 & 10 & 73 & 364 & 169 & 3 & 120 \\
\hline & $\mathrm{A}_{\mathrm{t}}(\mathrm{ha})$ & 378 & 1154 & 1379 & 4674 & 24 & 440 & 516 & 1357 & 16 & 752 \\
\hline & D (a) $\%$ & 40,5 & 16,6 & 75,1 & 63,8 & 41,7 & 16,6 & 70,5 & 12,5 & 18,8 & 16,0 \\
\hline \multirow{3}{*}{1990} & $\mathrm{~A}_{\mathrm{m}}(\mathrm{ha})$ & 146 & 170 & 1018 & 3158 & 3 & 98 & 557 & 124 & 5 & 217 \\
\hline & $\mathrm{A}_{\mathrm{t}}$ (ha) & 465 & 1152 & 1530 & 4827 & 24 & 632 & 779 & 436 & 24 & 820 \\
\hline & D (a) $\%$ & 31,4 & 14,8 & 66,5 & 65,4 & 12,5 & 15,5 & 71,5 & 28,4 & 20,8 & 26,5 \\
\hline \multirow[t]{2}{*}{$\mathrm{D}_{1990}-\mathrm{D}_{1984}$} & & $-9,1$ & $-1,9$ & $-8,5$ & 1,6 & $-29,2$ & $-1,1$ & 1,0 & 16,0 & 2,1 & 10,5 \\
\hline & $\mathrm{A}_{\mathrm{m}}(\mathrm{ha})$ & 88 & 106 & 174 & 176 & 434 & 644 & 337 & 2321 & 0,27 & 73 \\
\hline \multirow[t]{2}{*}{2000} & $\mathrm{~A}_{\mathrm{t}}(\mathrm{ha})$ & 273 & 776 & 807 & 504 & 1064 & 1238 & 1085 & 4441 & 0,36 & 501 \\
\hline & D (a) $\%$ & 32,2 & 13,7 & 21,6 & 34,9 & 40,8 & 52,0 & 31,1 & 52,3 & 75,0 & 14,6 \\
\hline \multirow[t]{2}{*}{$\mathrm{D}_{2000}-\mathrm{D}_{1990}$} & & 0,8 & $-1,1$ & $-45,0$ & $-30,5$ & 28,3 & 36,5 & $-40,4$ & 23,8 & 54,2 & $-11,9$ \\
\hline & $\mathrm{A}_{\mathrm{m}}$ (ha) & 159 & 130 & 1280 & 864 & 51 & 53 & 390 & 1454 & N.A & 176 \\
\hline \multirow[t]{2}{*}{2011} & $\mathrm{~A}_{\mathrm{t}}(\mathrm{ha})$ & 334 & 734 & 1801 & 2869 & 405 & 513 & 427 & 2629 & N.A & 976 \\
\hline & D (a) $\%$ & 47,6 & 17,7 & 71,1 & 30,1 & 12,6 & 10,3 & 91,3 & 55,3 & N.A & 18,0 \\
\hline \multirow[t]{2}{*}{$\mathrm{D}_{2011-} \mathrm{D}_{2000}$} & & 15,4 & 4,1 & 49,5 & $-4,8$ & $-28,2$ & $-41,7$ & 60,3 & 3,0 & N.A & 3,5 \\
\hline & $\mathrm{A}_{\mathrm{m}}$ (ha) & 37 & 301 & 927 & 1308 & 846 & 70 & 301 & 1160 & N.A & 54 \\
\hline \multirow[t]{2}{*}{2015} & $\mathrm{~A}_{\mathrm{t}}(\mathrm{ha})$ & 260 & 1003 & 1136 & 2761 & 1639 & 342 & 525 & 2711 & N.A & 313 \\
\hline & D (a) $\%$ & 14,2 & 30,0 & 81,6 & 47,4 & 51,6 & 20,5 & 57,3 & 42,8 & N.A & 17,3 \\
\hline $\mathrm{D}_{2015}-\mathrm{D}_{2011}$ & & $-33,4$ & 12,3 & 10,5 & 17,3 & 39,0 & 10,1 & $-34,0$ & $-12,5$ & N.A & $-0,8$ \\
\hline $\mathrm{D}_{2015-} \mathrm{D}_{1984}$ & & $-26,2$ & 13,4 & 6,5 & $-16,4$ & 10,0 & 3,9 & $-13,2$ & 30,3 & N.A & 1,3 \\
\hline
\end{tabular}

A: Water bodies B: Grassland savannah C: Hyphaene benguellensis forest D: Wooded savannah D*: Shrub savannah E: Burned areas F: Bare soils G: Aquatic vegetation H: Cultivated areas I: Dense forest J: Built areas **: Very low or no significant values (I), NA: Not Applicable (I) because of the dense forest disappearance.

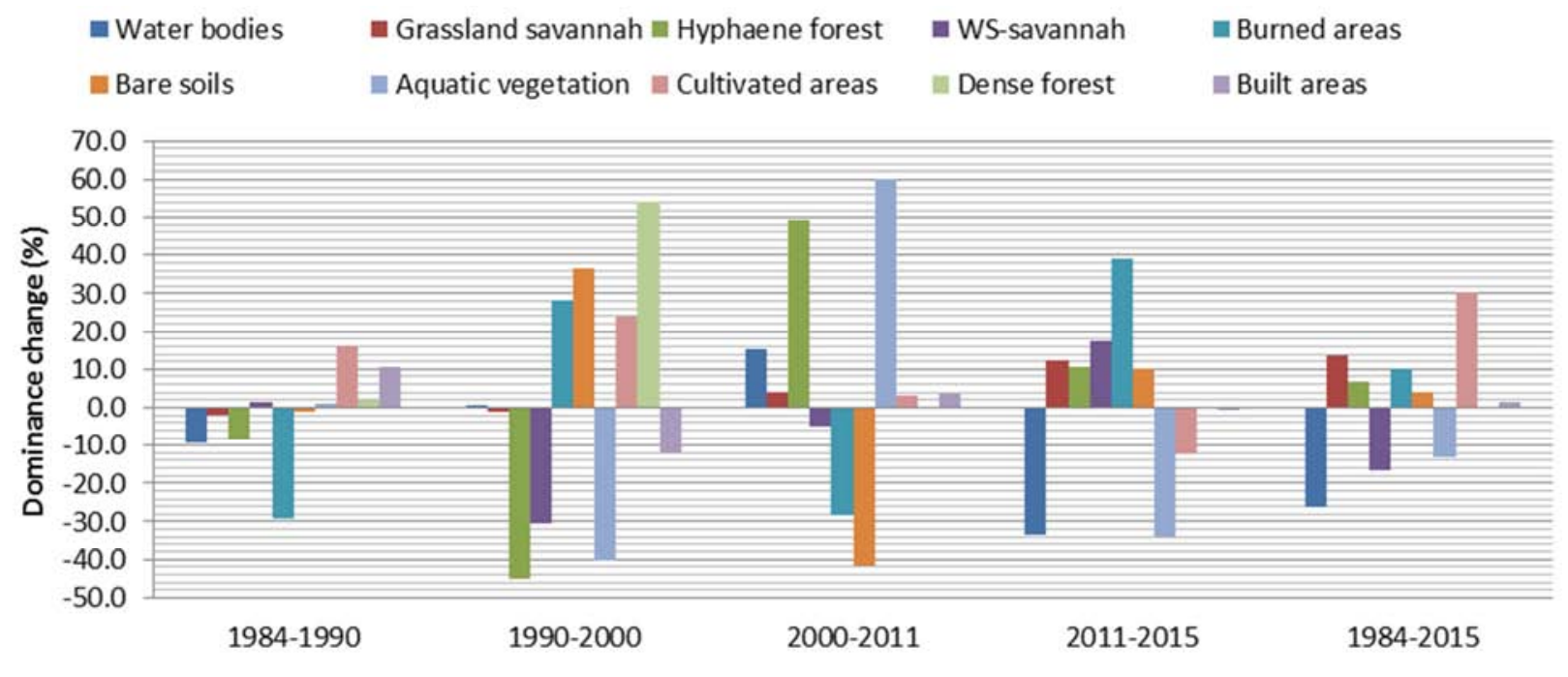

Figure 14. Variation of the class dominance values between 1984 and 2015.

In 2015, the weakly fragmented classes are Hyphaene benguellensis forest (81.6\%), aquatic vegetation (57.3\%) and burned areas $(51.6 \%)$. The moderately fragmented classes are shrub savannah $(47.4 \%)$, cultivated areas $(42.8 \%)$ and grassland savannah $(30.0 \%)$. Bare soils $(20.5 \%)$, built-up areas $(17.3 \%)$ and water bodies $(14.2 \%)$ are highly fragmented (Table 8 ). Compared to the baseline situation in 1984, there has been a negative tendency towards consolidation of the main anthropized classes (cultivated/burned areas) into large stable blocks since 2000 and a dislocation of important vegetation classes (shrub/wooded savannah).

\subsubsection{Trend Indices and Evolutionary Trends}

The synthetic statistics of the landscape dynamics which have been used to determine periodical trend indices and evolutionary trends are derived from transition matrices and intermediate calculations of specific parameters (Table 9).

The trend indices values which were calculated using data from Table 9 according to the methodological steps given in Table 10 are as follows: $(38,6) ;(78,-82) ;(65,22) ;(58,-36)$ and $(77,-64)$. The trend indices classes corresponding to the indices values are 2D, 4a, 3D, 3c and $4 \mathrm{~b}$ (Table 10). The resulting evolutionary trends which combine the two types of trend indices are "a moderate evolution (2)" with "a low positive trend (D)"; "a very strong evolution (4)" with "a very strong negative trend (a)"; "a strong evolution (3)" with "a low positive trend (D); "a strong evolution (3)" with "a moderate negative trend (c)" and "a very strong evolution (4)" with a strong negative trend (b)" (Table 1). 
Table 9. Synthetic statistics of landscape dynamics between 1984 and 2015.

\begin{tabular}{|c|c|c|c|c|c|}
\hline \multirow{2}{*}{ Landscape processes (\%) } & \multicolumn{5}{|c|}{ Periods of study } \\
\hline & 1984-1990 & $1990-2000$ & 2000-2011 & 2011-2015 & 1984-2015 \\
\hline Global stability (S) & 62 & 22 & 35 & 42 & 23 \\
\hline Progression $(\mathrm{P})$ & 20 & 8 & 40 & 19 & 14 \\
\hline Regression (R) & 16 & 61 & 9 & 25 & 55 \\
\hline Neutral Conversions $\left(C_{n}\right)$ & 2 & 9 & 16 & 14 & 8 \\
\hline Total land coverage & 100 & 100 & 100 & 100 & 100 \\
\hline Degradation $\left(R+C_{n}\right)$ & 18 & 70 & 25 & 40 & 63 \\
\hline Change rate $(\mathrm{Tc})$ & 38 & 78 & 65 & 58 & 77 \\
\hline Relative progression $(\mathrm{X})$ & 53 & 9 & 61 & 32 & 18 \\
\hline Relative degradation $(\mathrm{Y})$ & 47 & 91 & 39 & 68 & 82 \\
\hline
\end{tabular}

Table 10. Trend indices (TI) values and classes from 1984 to 2015.

\begin{tabular}{lll}
\hline \multirow{2}{*}{ Period } & Methodological steps for the calculation of trend indices values & T. I values \\
\cline { 2 - 4 } $1984-1990$ & $\left.\left\{\mathrm{~T}_{\mathrm{c}}=(100-\mathrm{S})=\mathrm{x} \epsilon\right] \alpha-\beta\right]$ class $\mathrm{i} ; \mathrm{Bc}=(\mathrm{X}-\mathrm{Y})=\mathrm{y} \epsilon[\gamma-\delta](>,<) 0 ;$ class $\left.\mathrm{j}\right\}$ & $\mathrm{I}_{\mathrm{t}}=[(\mathrm{x}, \mathrm{y}) ; \mathrm{ij}]$ \\
$1990-2000$ & $\left.\left.\mathrm{~T}_{\mathrm{c}}=(100-62)=38 \epsilon\right] 25-50\right]$ class $2 ; \mathrm{Bc}=(53-47)=6 \epsilon[0-25]>0 ;$ class $\mathrm{D}$ & {$[(38,6) ; 2 \mathrm{D}]$} \\
$2000-2011$ & $\left.\left.\mathrm{~T}_{\mathrm{c}}=(100-22)=78 \epsilon\right] 75-100\right]$ class $4 ; \mathrm{Bc}=(9-91)=-82 \epsilon[-100,-75[<0$ class a & {$[(78,-82) ; 4 \mathrm{a}]$} \\
$2011-2015$ & $\left.\left.\mathrm{~T}_{\mathrm{c}}=(100-35)=65 \epsilon\right] 50-75\right]$ class $3 ; \mathrm{Bc}=(61-39)=22 \epsilon[0-25]>0$ class $\mathrm{D}$ & {$[(65,22) ; 3 \mathrm{D}]$} \\
$1984-2015$ & $\left.\left.\mathrm{~T}_{\mathrm{c}}=(100-42)=58 \epsilon\right] 50-75\right]$ class $3 ; \mathrm{Bc}=(32-68)=-36 \epsilon[-50,-25[<0$ class $\mathrm{c}$ & {$[(58,-36) ; 3 \mathrm{c}]$} \\
\hline
\end{tabular}

As shown in Figure 15 below, neutral conversions are low compared to vegetation evolutions. The disappearance and appearance of vegetation are the most dominant landscape dynamics, particularly during periods 1990-2000, 2000-2011 and 1984-2015. They are more important than qualitative losses and gains of vegetation.

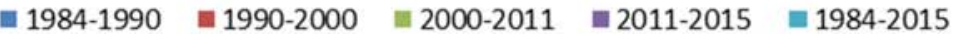

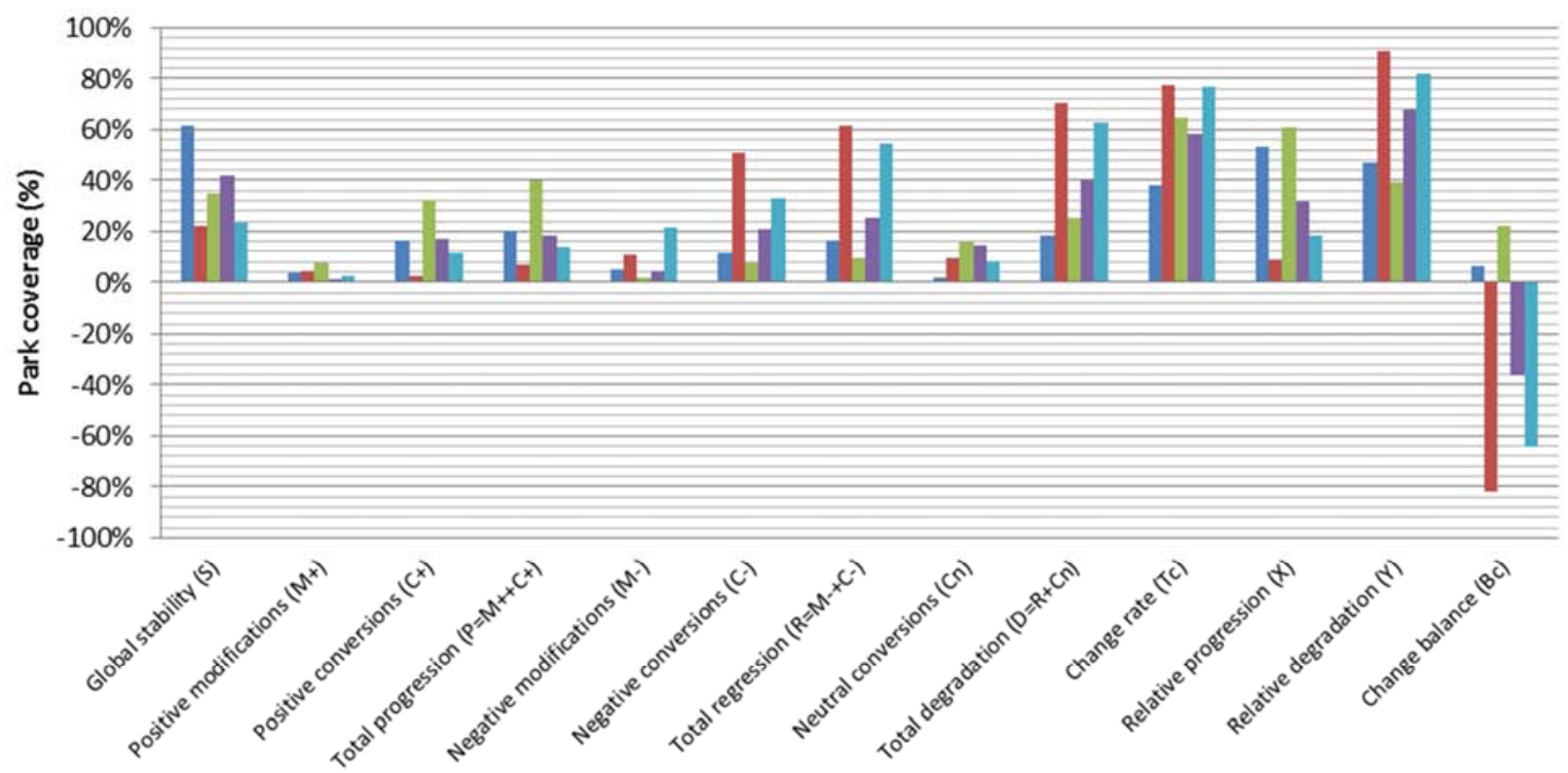

Figure 15. Evolution of landscape and vegetation dynamics from 1984 to 2015.

\section{Discussion}

\subsection{Land Cover Changes}

Between 1984 and 1990, the decline of the anthropized classes in general and of the cultivated areas in particular and the extension of the vegetation cover were explained by the evacuation of the inland populations after the creation of the park in 1980 and the existence of a rainfall surplus.

The extension of bare soils is justified by the deforestation of part of the protected area by the Institute of Agricultural
Sciences of Burundi for trials on non-native tree species.

Between 1990 and 2000, the large spread of the anthropized classes in general and of the cultivated areas in particular and the decline of the vegetation cover resulted from existence of deficit rainfall and the mass invasion and the anarchic exploitation of the park by many displaced people during the 1993 civil war $[43,5]$. This period saw a massive deforestation of the park, which practically eliminated the woody cover of the park.

From 2000 to 2011, the decline of the anthropized classes in 
general and of the cultivated areas in particular and the important recovery of the vegetation cover are explained by the insecurity in a large part of the park following the presence of armed bands, the gradual repatriation of displaced from war in 1993 and excess rainfall.

Between 2011 and 2015, the extension of the anthropized classes and the reduction of the vegetation cover result from intensive exploitation of the park despite the decree of evacuation of the populations of 2011 and the continuous decrease of the rainfall since 2012. The considerable extension of the burned areas is linked to the socio-political crisis triggered since April 2015; the park firing having been used by the authorities to prevent the installation of rebel movements.

Between 1984 and 2015 finally, the degradation of the vegetation cover which is mainly due to the extension of cultivated areas and burned areas, is justified by a quick riparian population growth and a very strong dependence on the resources of the park on one hand. The park dependent riparian populations have increased from 35,590 inhabitants in 1984 to 146,799 inhabitants in 2015; representing an annual growth rate of $10 \%$. In Central Africa indeed, previous studies have established a negative causality between population pressure and changes in forest cover $[44,45]$. On the other hand, the degradation has been caused by the instability of the conservation status, a centralized management and a high climate variability [20].

The fragmentation and multiplication of land cover classes are permanent processes in the Rusizi plain where the park is located. A previous study showed that there were four land cover classes in 1951, six classes in 1962 and seven classes in 1973 [26]. Cultural clearings and bushfires are the most important anthropogenic factors which are responsible for the evolution of the vegetation and the park itself. Between 1990 and 2000, intense tree cuts for domestic needs, bush fires and overgrazing have led to a high destruction of vegetation cover. The limited stability of the anthropized classes is caused by a great spatial mobility of illicit activities.

As shown by other studies elsewhere, the evolution of the park is continuously and strongly influenced by the opposite processes of agricultural intensification and land abandonment [46].

\subsection{Class Dominance Values and Spatial Processes}

The comparative analysis of the class dominance values and spatial processes showed a great correspondence between the two spatial transformation indicators which are affecting land cover classes (Tables 7-8). Between 1984 and 1990, the dominance decrease affecting burned areas was due to a patch dissection process while the consolidation of bare soils resulted from a patch creation process.

Between 1990 and 2000, the decrease in dominance that affected Hyphaene benguellensis forest and wooded savannah is justified by respective patch dissection and patch fragmentation processes. The increase in dominance affecting bare soils, burned areas and cultivated areas is explained by a patch creation process.
Between 2000 and 2011, the dominance decrease which was affecting bare soils and burned areas resulted from respective patch attrition and patch fragmentation processes. The dominance increase in Hyphaene benguellensis forest and water bodies is justified by a patch creation process.

From 2011 to 2015, the dominance decrease affecting water bodies was due to a patch attrition process. The dominance increase which affected burned areas and grassland savannah resulted from respective patch creation and aggregating processes.

Between 1984 and 2015 ultimately, the dominance decrease that affected water bodies and wooded savannah was the result of patch dissection and patch attrition processes. The dominance increase affecting cultivated areas and burned areas was due to patch aggregation and patch creation processes.

However, beyond the coherences observed in the whole, there are some specific situations that have particular explanations. For examples, between 1984 and 1990, the dominance increase that was affecting cultivated areas for a patch attrition process would be justified by maintaining only cotton crop plots of the Cotton Management Company after the evacuation of small holdings within the creation of the protected area.

Between 1990 and 2000, the decline in dominance that affected aquatic vegetation for a patch creation process was explained by the wetland farming in this dry period, which fragmented this vegetation formation into several islands.

\subsection{Spatial Processes, Landscape Dynamics and Evolutionary Trends}

The impact of spatial processes on the evolution of the park depends on the nature of the land cover classes they are affecting and their specific significance for conservation [37, 47]. For example, if patch creation and patch attrition processes are respectively negative and positive when affecting anthropized zones, they are exactly the reverse when they affect vegetation formations and water bodies referred to the park's conservation objectives.

The analytic results showed an important coherence between spatial processes, dominant landscape dynamics and evolutionary trends in the protected area. Between 1984 and 1990, the spatial processes observed in most vegetation formations (aggregation, creation), water bodies (enlargement) and in the most important anthropogenic class (cultivated areas) (attrition) led to an appreciable development of vegetation cover and wetlands. The predominant landscape dynamic is a densification of the vegetation cover which is marked by savannahs formation and reforestation (Table 2, Figures 6 and 15).

Between 1990 and 2000, the spatial processes encountered in most vegetation formations (attrition, dissection, fragmentation), water bodies (attrition) and the most important anthropized classes (cultivated areas, burned areas, bare soils) (creation) have resulted in significant declines in vegetation cover and wetlands. The dominant landscape dynamic is an opening up of the environment which is 
characterized by anthropisation by savannah destruction and deforestation (Table 3, Figures 7 and 15).

From 2000 to 2011, the spatial processes noted in the most important vegetation formations (shrub savannah, Hyphaene benguellensis forest) (creation), water bodies (creation) and dominant anthropized classes (cultivated areas, burned areas) (attrition, fragmentation) led to an extension of vegetation cover and wetlands. The predominant landscape dynamic is a densification of vegetation cover which is characterized by savannah formation and reforestation (Table 4, Figures 8 and 15).

From 2011 to 2015 , the spatial processes observed in the most important vegetation formations (shrub savannah, Hyphaene benguellensis forest) (attrition), water bodies (attrition) and dominant anthropized classes (cultivated areas, burned areas) (aggregation, creation) led to a decline in vegetation cover and wetlands. The predominant landscape dynamic is an opening up of the environment which is marked by anthropisation by savannah destruction and deforestation (Table 5, Figures 9 and 15).

Between 1984 and 2015 lastly, the spatial processes that affected the majority of vegetation formations (attrition, dissection), water bodies (dissection) and dominant anthropized classes (cultivated areas, burned areas) (aggregation, creation) resulted in a decline in vegetation cover and wetlands. The dominant landscape dynamic is an opening up of the environment, which is characterized by anthropisation by savannah destruction and deforestation (Table 6, Figures 11 and 15).

The correspondence between spatial structures indices and landscape dynamics is established by other studies (Barima and al, 2009). Also, the negative impact of patch dissection, fragmentation and suppression processes on the evolution of vegetation cover was confirmed by other studies on forest degradation [48].

We note that periods with positive developments are characterized by more spatial processes than those with negative evolutions (Figures 12-13). Since the development of vegetation cover is the main objective of the park's conservation, the spatial processes and the dominant landscape dynamics observed during the periods 1984-1990 and 2000-2011 have been favorable to conservation. The dominant spatial processes and landscape dynamics noted during the periods 1990-2000, 2011-2015 and 1984-2015 were unfavorable to conservation. The trend indices values showed that the Rusizi Park has experienced highly varied evolutionary trends (Table 10).

Periods 1984-1990 and 2000-2011 were marked by positive developments. The developments of vegetation cover induced by the evacuation of the interior populations and the favorable climatic conditions resulted respectively in "a moderate evolution (2)" with "a low positive trend (D)" whose value is $\mathrm{T}_{\mathrm{i}}[(38,6) ; 2 \mathrm{D}]$ and "a strong evolution (3)" with "a low positive trend (D)" whose value is $\mathrm{T}_{\mathrm{i}}[(65,22) ; 3 \mathrm{D}]$.

Periods 1990-2000 and 2011-2015 were characterized by negative developments. The regression of the vegetation cover due to unregulated occupation and exploitation of the park following the civil war of 1993 and unfavorable climatic conditions successively led to "a very strong evolution (4)" with "a very strong negative trend (a)" whose value is $\mathrm{T}_{\mathrm{i}}[(78$, -82); 4a] and "a strong evolution (3)" with "a moderate negative trend (c)" whose value is $\mathrm{T}_{\mathrm{i}}[(58,-36) ; 3 \mathrm{c}]$.

From 1984 to 2015, the park experienced a very significant negative development. The considerable decline in vegetation cover caused by important agro-pastoral pressures and an important climate variability led to "a very strong evolution (4)" with "a strong negative trend (b)" whose value is $\mathrm{T}_{\mathrm{i}}[(77$, $-64)$; 4b]. On one hand, the period 1990-2000 has been the most devastating for the protected area.

Land cover changes have affected $78 \%$ of the park's surface; $91 \%$ being in degradation and $9 \%$ in progression; resulting in a $82 \%$ negative balance. On the other hand, the period 2000-2011 was the most beneficial for conservation. Land cover changes have affected $65 \%$ of the park's area; $61 \%$ being in progression and $39 \%$ in degradation; resulting in a $22 \%$ positive balance. At the global scale of the study (1984-2015), the park was overhauled on $77 \%$ of its extent; $82 \%$ being degraded and $18 \%$ increasing; resulting in a $64 \%$ negative balance.

The evolutionary trends of the Rusizi Park are thus determined by the intensity of exploitation pressures and local climatic conditions. They have all been confirmed qualitatively by the results of interviews with managers and partly by certain studies $[4,5]$.

Unlike indicators which describe only the surface variations in land cover [49] or anthropogenic and agricultural pressures [50] without giving global evolutions, the trend index is an inclusive indicator which makes it possible to establish the overall evolutionary balance of a protected area during a considered period on the basis of conservation objectives.

\section{Conclusion}

The case study shows the utility of geospatial analysis techniques and field investigations in the development of indicators for the assessment of the management and evolution of protected areas. The results showed that the Rusizi Park has been characterized by periodic changes, both positive and negative. At the global scale of the study (1984-2015), it experienced a very high degree of degradation which was characterized by a strong regression of the vegetation cover in favor of the anthropized zones which are dominated by cultivated and burned areas. Negative developments were observed during periods of anarchic exploitation and deficit rainfall whereas positive ones appeared in times of evacuations of the farmers and of excess rainfall. These observations show that the main determinants of the evolution of the park are anthropogenic pressures and the variability of climatic conditions. Despite their wide range, the spatial transformation processes leading to different evolutions are dominated by patch creation and patch attrition processes which lead to deep contrasting and close rearrangements that are not favorable to the desired changes over time. The results also revealed a great coherence between spatial indicators and trend indices that 
characterized the evolutionary trends. Patch degradation processes lead to negative evolutions when they affect vegetation formations and positive developments if they affect anthropized zones and vice versa, for patch development processes. In general, class dominance decreases are linked to patch degradation processes and vice versa.

\section{References}

[1] Nindorera D., Hakizimana F. Nzigidahera B., "20 years of existence of the Natural Reserve of Rusizi (1980-2000)" National Institute for the Environment and Nature Conservation in Burundi, 2000.

[2] IUCN-PACO., "Burundi Parks and Reserves: Assessing the Effectiveness of Protected Area Management". IUCN / PACO, Ouagadougou, Burkina Faso, 2011, 107p.

[3] Debonnet G. and Wakana M., "Rusizi National Park: Management Plan. Natural Resources Protection Support Project (NPA)". GTZ / INECN, 1996. 99 p.

[4] Ntakimazi G, Nzigidahera B, Nicayenzi F. and West K, "The status of biological diversity in the aquatic and terrestrial environments of the Rusizi Delta". RAF/92/G32, UNDP-GEF, 2000, 51p.

[5] Nzigidahera, B, "Study of the evaluation of the impacts of anthropogenic actions and the degree of disappearance of biodiversity: Proposal for a sustainable management plan for the Rusizi Nature Reserve, a proposed Biosphere Reserve". INECN, UNESCO-MAB,.2003. 59p.

[6] Cayate M. L and Kakunze A. C, "Management Plan of the Rusizi national Park". Burundian Office for the Protection of the Environment, 2015, 120p.

[7] Clerici N, Bodini A, Eva H, Grégoire JM, Dulieu D, Paolini C, "Increased Isolation of Two Biosphere Reserves and Surrounding Protected Areas" (WAP: W-Arly-Pendjari, Ecological Complex, West Africa). J Nat Conservation 15, 2007, p. 26-40.

[8] Jeremy B, Youssoufou S, Yahaya S, Jean C, Laure G, Chantal $\mathrm{KZ}$, et al., "Identification of ecological indicators for monitoring ecosystem health in the trans-boundary W Regional Park: A pilot study". Biological Conservation 238, 2007, p. 73-88.

[9] Rodríguez, J. P., J. K. Balch, and K. M. Rodríguez-Clark, "Assessing extinction risk in the absence of species-level data: quantitative criteria for terrestrial ecosystems". Biodiversity and Conservation 16, 2007, p. 183-209.

[10] Forman, R. T. T., "Some general principles of landscape and regional ecology". Landscape Ecology 10, 1995b, p. 133-142.

[11] McGarigal K. and Marks B. J, "Fragstats: Spatial Pattern Analysis for Quantifying Structure". Department of Agriculture, Pacific Northwest Research Station General Technical Report PNW-GTR-351, 1995. Oregon, USA.

[12] Hargis C. D, Bissonette J. A and David J. L, "Understanding measures of landscape pattern". In: Wildlife and landscape ecology (eds. Bissonette J. A.), 1997. p. 231-261. Springer, Berlin Heidelberg, New York.

[13] Hockings M., Stolton S., Leverington F., Dudley N., Courrau J,
"Evaluating Effectiveness: A Framework for Assessment Management Effectiveness of Protected Areas" 2nd Edition. No. 14. IUCN, Gland, Switzerland, 2006), Xiv + 105p.

[14] IUCN-PAPACO, "Reinforce the conservation of the protected areas of Africa". Synthesis of Weotenga meeting (Burkina-Faso, 25-27 October 2011, 2012, 58p.

[15] Ulbricht K. A. and Heckenford WD, "Satellite images forests". ISPRS Journal of Photogrammetry and Remote Sensing, vol. 53, 1998, p. 235-243.

[16] Girard, M. C and Girard, C., "Remote sensing data processing”. Paris, Ed. Dunod, ISBN: 2-1000-4 185-1, 1999, $529 \mathrm{p}$.

[17] Inglada, J., "State of the art in detecting changes in remote sensing images". Toulouse, CNES, 2001, 20p.

[18] Foody G. M., "Status of land covers classification accuracy assessment". Remote Sensing of Environment, vol. 80, 2002, p. $185-201$.

[19] Mayaux P., Eva H., Palumbo I., Grégoire J.-M., Fournier A., Sawadogo L, "The contribution of space technology to the management of protected areas in West Africa". In: Fournier A., Sinsin B., Mensah G. A. (Eds). Which protected areas for West Africa? Conservation of biodiversity and development. Paris, France, IRD, coll. Colloquia and seminars, 2007, p. 321-328.

[20] Sinarinzi, E., "Study of vulnerability and adaptation to climate change in Burundi: climate and water. Preparation of the National Action Plan for Adaptation to Climate Change" (PANA) UNDP-GEF / MINATTE, 2006, 57p.

[21] Tabopda W. G. and Fotsing J.-M., "Quantification of the evolution of vegetation cover in the Laf-Madjam forest reserve in northern Cameroon by satellite remote sensing". Drought, 21 (3), 2010, p. 169-178.

[22] Caloz R., Lazer T. J., Willemin G., "Creation of an ortho image using a digital elevation model: influences of radiometric resampling modes. In: Dubois J.-M. M., Cavayas F., Lafrance P. (Ed.). Remote sensing applied to thematic and topographical mapping. Fourth scientific days of the UREF Remote Sensing Network, Montreal, 21-23 October 1991, 1993, Québec, Canada, Quebec University Presses 17-30.

[23] Mas J. F., "A review of methods and techniques for remote sensing of change". Canadian Journal of Remote Sensing, 26 (4), 2000, p. 349-362.

[24] Bonn F. and Rochon G., "Precise remote sensing. Principles and methods". Presses of the University of Quebec, Canada, vol. 1, ISBN: 2-7605-0613-4, 1992, 485 p.

[25] Congalton R. G, "A review of the accuracy of classifications of remotely sensed data". Remote Sensing of Environment, 37, 1991, p. 35-46.

[26] Reekmans, M., "The vegetation of the plain of the lower Rusizi (Burundi). Bull. Jard. Bot. Belg., 50, 1980, p. 401-444.

[27] Schlaepfer, R., "Analysis of the dynamics of the landscape. Teaching sheet 4.2", Laboratory of Ecosystem Management, Lausanne Polytechnic School, Switzerland, 2002.

[28] Robin M., "Remote sensing, from satellites to GIS. A comprehensive analysis of the process of creating an essential type of geographic information". Nathan University. ISBN: 2 -0919-1224-7, 2002, 318 p. 
[29] Alun, J. and Clark, J, "Driving forces behind European land use change: an overview". Claude Resource Paper \# 1, 1997.

[30] Baulies, X. I. And Szejwach, G. (ed.), "Cover of research and development”. LUCC Data requirements workshop, Barcelona 11-14 November 1997, LUCC report series 3, 1997.

[31] Di Gregorio A. and Jansen L. J. M, "Land Cover Classification System: Classification Concepts and User Manual, FAO, Rome", 2000, (Www.fao.org).

[32] Oloukoi J, Mama VJ. And Agbo FB, "Modeling the dynamics of land cover in the Department of Hills in Benin". Remote sensing 6 (4), 2013, p. 305-323.

[33] Fortin M.-J., "Spatial analysis in ecology: statistical and landscape scale issues". Ecoscience, 9, 2002, iii-v.

[34] Bogaert J. and Mahamane A., "Landscape Ecology: Targeting the configuration and spatial scale". Annals of Agronomic Sciences of Benin, 7, 2005, p. 39-68.

[35] Bamba I., Barima Y. S. and Bogaert, J, "Influence of population density on the spatial structure of a forest landscape in the Congo Basin in D. R. Congo". Tropical Conservation Science Vol. 3 (1), 2010, p. 31-44. Available online: www.tropicalconservationscience.org. Accessed February 25, 2016.

[36] Giles R. H. and Trani M. K., "Key elements of landscape pattern measures". Environmental Management, 23, 1999, p. 477-481.

[37] Bogaert J, Ceulemans R, Salvador-Van Eysenrode, D, "Decision tree algorithm for detection of spatial processes in landscape transformation". About. Manage. 33 (1), 2004, p. 62-73.

[38] Barima S. S., Barbier N, Bamba I, Traore D, Lejoly J. and Bogaert J, "Landscape dynamics in Ivory Coast forest-savannah transition. Wood and Forest of the Tropics, 63 (299), 2009, p. 15-25.

[39] International Tropical Timber Organization, "Reintegrate secondary forests into the landscape". ITTO Tropical Forest Update 10/4/2002, 2002.

[40] Anderson James R, "Land use classification schemes used in selected recent geographic applications of remote sensing" Photogrammetric Engineering and Remote Sensing (PE \& RS), Vol. 37, no. 4, 1971, pp. 379-387.

[41] Landis J R and Koch G. G, "The measure of compliance for categorical data. Biometr 33: p. 159-74 landscape ecology in biological conservation. (Eds Gutzwiller K. J.), 1977, p. 34-52. Springer, Berlin Heidelberg, New York.

[42] Caloz R. and Collet C., "Precise remote sensing. Volume 3: Digital Remote Sensing Image Processing (Francophone Universities)". Quebec, Canada, Polytechnic Presses of Quebec, ISBN: 2 -7605-1145-6, 2001, 368 p.

[43] United Nations Development Program, "Effect of the socio-political crisis on the environment in Burundi". Bujumbura, 1996, 185p

[44] Bogaert J and Barima Y. S. S, "On the transferability of concepts and its significance for landscape ecology". J. Mediter. Ecol., 2008, p. 933-37.

[45] Bamba I, Mama AD, Neuba FR, Koffi KJ, Traore D, Visser M., "Influence of anthropogenic actions on the spatio-temporal dynamics of land cover in the province of Bas-Congo (DR Congo)". Science \& Nat 5, 2008, 49-60.

[46] Farina A., "Landscape ecology in action". Kluwer Academic Publishers, Dordrecht. The Netherlands, 2000.

[47] Eva H. D, Brink A. B and Simonetti D., "Monitoring land cover dynamics in Sub-Saharan Africa. A pilot study using Earth observing satellite data from 1975 and 2000". JRC Scientific and Technical Reports, 2006, 40p.

[48] Groves R. H., "Ecological indicators of landscape degradation. In: Landscape disturbance and biodiversity in mediterranean-type ecosystems. (Eds Rundel PW, Montenegro G, Jaksic FM), 1998, pp 55-62. Springer, Berlin Heidelberg, New York.

[49] Noyola-Medrano, M. C., "The present morphological evolution of the Sierra Chichinautzin Volcanic Field (Mexico) from the tomomorphometric analysis of the slag cones and the change in land cover." Doctoral thesis. Paris University 7. 2006.

[50] Hartley, A., Nelson, A., Buchanan, G., Mayaux, P. and J-M Gregoire, "Prioritizing Protected Areas in Africa based on irreplaceability and threats: Towards a decision support tool for country level assessment". European Commission, Luxembourg, 2007. 